
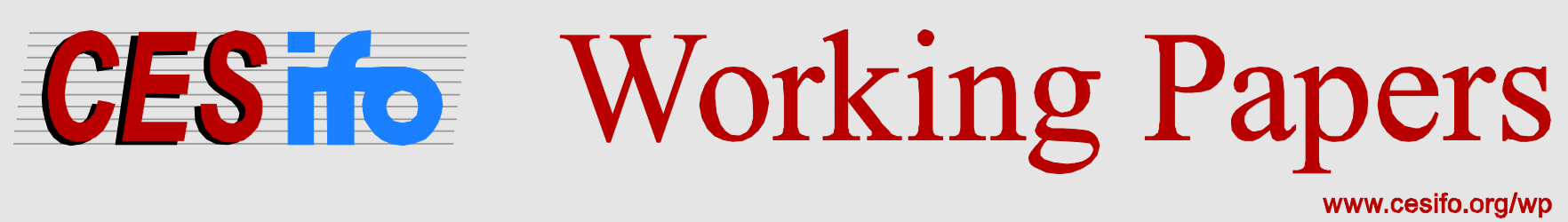

\title{
Efficiency, Welfare, and Political Competition
}

\author{
Felix J. Bierbrauer \\ Pierre C. Boyer
}

CESIFO WORKING PAPER NO. 4814

CATEGORY 1: PUBliC FinANCE

MAY 2014

An electronic version of the paper may be downloaded

- from the SSRN website:

- from the RePEc website:

- from the CESifo website:

WwW.SSRN.com

www.RePEc.org

www.CESifo-group.org/wp

\section{CESifo}




\title{
Efficiency, Welfare, and Political Competition
}

\begin{abstract}
We study political competition in an environment in which voters have private information about their preferences. Our framework covers models of income taxation, public-goods provision or publicly provided private goods. Politicians are vote-share-maximizers. They can propose any policy that is resource-feasible and incentive-compatible. They can also offer special favors to subsets of the electorate. We prove two main results. First, in a symmetric equilibrium, policies are surplus-maximizing and hence first-best Pareto-efficient. Second, there is a surplus-maximizing policy that wins a majority against any welfare-maximizing policy. Thus, in our model, policies that trade off equity and efficiency considerations are politically infeasible.
\end{abstract}

JEL-Code: C720, D720, D820, H410.

Keywords: political competition, asymmetric information, public goods, non-linear income taxation, redistributive politics.

Felix J. Bierbrauer

CMR - Center for Macroeconomic

Research / University of Cologne

Albert-Magnus Platz

Germany-50923 Cologne

bierbrauer@wiso.uni-koeln.de

\author{
Pierre C. Boyer \\ University of Mannheim \\ Department of Economics \\ Germany-68131 Mannheim \\ pierre.boyer@uni-mannheim.de
}

May 13, 2014

We thank Philippe De Donder, Hans Peter Grüner, Emanuel Hansen, Laurence Jacquet, Eckhard Janeba, Philippe Jehiel, Hideo Konishi, Kai Konrad, Jean-François Laslier, Michel Le Breton, Étienne Lehmann, Florian Morath, Jenny Simon, Thomas Tröger, and Carl Christian von Weizsäcker for very helpful comments and discussions, as well as seminar and conference participants at École Polytechnique, Mannheim University, Boston College, Cologne University, Marburg University, SITE Stockolm, SFBTR15 in Berlin, seminar TOM at Paris School of Economics, MPI in Bonn, PET 2013 in Lisbon, EEAESEM 2013, seminar Hotelling at ENS-Cachan, Workshop Voting Theory and Elections at University Cergy-Pontoise, Workshop on the Economics of Taxation at ENS-Cachan, IX Tax-Day at MPI in Munich, 2014 ASSA meeting in Philadelphia. The second author gratefully acknowledges the Collaborative Research Center 884 for financial support. The second author also thanks the Thema at University Cergy-Pointoise and the ENS-Cachan for their hospitality and financial support. The usual disclaimer applies. 


\section{Introduction}

Mechanism design has become the dominant paradigm for a normative analysis of publicly provided goods or tax systems. The strength of this approach is that it provides a rigorous justification of the constraints that a policy-maker faces. Available technologies and endowments give rise to resource constraints, privately held information gives rise to incentive compatibility constraints, predetermined institutional arrangements may generate another layer of constraints such as, for instance, the requirement of voluntary participation. Political economy approaches, by contrast, often provide additional restrictions on the set of admissible policies. These restrictions lack theoretical foundations, but are imposed for pragmatic reasons, e.g. because they ensure the existence of a Condorcet winner in a model of political competition.

For instance, for redistributive income taxation, a normative analysis in the tradition of Mirrlees (1971) characterizes a welfare-maximizing income tax with no a priori assumption on the functional form of the tax function. A well-known political economy approach to this problem by Meltzer and Richard (1981) is based on the assumption that all individuals face the same marginal tax rate, and that tax revenues are used to finance a uniform lump-sum transfer to all citizens. One can thereby show that the preferred policy of the voter with median income wins a majority against any alternative policy proposal. This result, however, does not extend to the domain of non-linear income tax schedules: the median voter's preferred non-linear income tax schedule does not win a majority against an alternative tax schedule under which the median level of income is taxed more heavily but all other incomes are treated more favorably.

More generally, the use of different models in normative and positive public finance makes it difficult to provide answers to the following questions: Does political competition generate Pareto-efficient outcomes? Does it generate welfare-maximizing outcomes? Is there a sense in which political competition gives rise to political failures, in analogy to the theory of market failures.

In this paper, we study political competition from a mechanism design perspective. Our framework covers both publicly provided goods and redistributive income taxation. We ask which mechanism emerges as a result of political competition under the assumption that a politicians' objective is to win an election, as in Downs (1957). Politicians can propose any mechanism that is incentive-compatible and resource-feasible. Moreover, we consider a policy domain that is larger than the one usually considered in normative treatments of public goods provision or income taxation: we give politicians the possibility to accompany, say, a proposed income tax schedule with a distribution of favors in the electorate. These favors are unrelated to the voters's preferences for publicly provided goods or their productive abilities, and, they would not be needed to achieve a Paretoefficient, or welfare-maximizing outcome. Politicians may still want to use them so as 
to generate more support for their policy platform. In political economy analysis, this is often referred to as pork-barrel spending. $1^{1}$ Finally, we assume that the preferences of voters are quasi-linear in the consumption of private goods.

We prove two Theorems. Theorem 1 can be interpreted as a first welfare theorem for political competition. It claims that, in any symmetric equilibrium, both politicians propose a surplus-maximizing policy. Thus, the political equilibrium allocation cannot be Pareto-improved upon in the set of resource-feasible policies. For a problem of income taxation, Theorem 1 implies that, in a political equilibrium, there is no use of distortionary tax instruments. Transfers of resources between voters take place in equilibrium, but are financed exclusively with non-distortionary lump-sum transfers $2^{2}$ For a model that involves the provision of a non-rival good, such as clean air or national defense, Theorem 1 implies a political equilibrium allocation that satisfies the efficiency condition which is known as the Samuelson rule, Samuelson (1954). For a model with publicly provided private goods, such as health care or education, Theorem 1 implies that the political equilibrium allocation gives rise to the same consumption levels as a competitive market allocation, i.e. marginal benefits of consumption are equalized across voters.

Theorem 2 is concerned with the question whether welfare-maximizing policies have a chance in the political process. To formalize this question, we introduce an assumption of risk-aversion. This assumption implies that a welfare-maximizing policy does not involve pork-barrel spending: from an ex-ante perspective, all voters prefer an equal treatment over a random allocation of special treatments. We impose no further restriction on the set of welfare-maximizing policies, i.e. any policy that maximizes a weighted average of the voters' utility levels over the set of incentive-compatible and feasible policies will be referred to as a welfare-maximizing policy. Theorem 2 then asserts that there is a policy that wins a majority against any welfare-maximizing policy. This policy is surplus-maximizing and involves a random allocation of special treatments. For a model of income taxation, the theorem implies that any welfare-maximizing policy that involves a transfer of resources from richer individuals to poorer individuals can be defeated by a policy that has no such transfers, but distributes favors in such a way that many rich and some poor voters will be attracted.

The reminder is organized as follows. The next section reviews the related literature. Section 3 discusses an illustrative example. Section 4 contains our main results for a model of with publicly provided goods. The proofs are in Section 5. Section 6 covers a model of income taxation. We discuss equilibrium existence in Section 7. Section 8 relates our analysis to other models of political competition. The last section contains

\footnotetext{
${ }^{1}$ Myerson (1993) and Lizzeri and Persico (2001) characterize the equilibrium allocation of pork-barrel spending for economies with complete information on preferences and technologies. We use some of their insights. Our focus, however, is on environments with private information.

${ }^{2}$ In Section 8 we relate our analysis to other models of political competition and discuss how our framework would have to be modified so as to generate predictions that are empirically more plausible.
} 
concluding remarks. In the body of the text, we present our results under the assumption that there is a continuum of voters, the finite population analogue is presented in the Appendix. We also relegate some of our proofs to the Appendix.

\section{Related literature}

Our work is related to the game-theoretic literature on the "divide-the-dollar-game". These are models of political competition in which a policy proposal specifies how a cake of a given size should be distributed among voters ${ }^{3}$ Our model differs in that policy proposals affect the size of the cake that is available for redistribution. Also, there is private information on preferences so that not only resource constraints but also incentive compatibility constraints have to be taken into account. Still our equilibrium characterization makes use of insights which have been provided by this literature, in particular, by Myerson (1993).

Our basic setup is taken from the normative literature that uses a mechanism design approach to study public goods provision, or income taxation. The main difference between our approach and these literatures is that we replace the fictitious benevolent mechanism designer by the forces of political competition. The normative literature on public goods provision has, by and large, focussed on the question whether surplusmaximizing outcomes can be obtained if incentive compatibility and/or participation constraints have to be respected 4 We do not impose participation constraints in our analysis. We take it as given that the government uses its coercive power to finance publicly provided goods. The literature on optimal income taxation in the tradition of Mirrlees (1971) has analyzed the conditions under which a welfare-maximizing policy involves distortionary taxes ${ }^{5}$

Some authors have related the mechanism design approach to public-goods provision to the institutional arrangements of a direct democracy $\left.\right|^{6}$ Our approach is different in that

\footnotetext{
${ }^{3}$ Contributions to this literature include Myerson (1993), Lizzeri (1999), Laslier and Picard (2002), Roberson (2006), Sahuguet and Persico (2006), Carbonell-Nicolau and Ok (2007), Crutzen and Sahuguet (2009), Casamatta, Cremer and De Donder (2010), and Roemer (2011).

${ }^{4}$ Green and Laffont (1977) have shown that ex post efficiency is out of reach with the solution concept is dominant strategy equilibrium. d'Aspremont and Gérard-Varet (1979) have shown that efficiency can be reached with the more permissive solution concept of a Bayes-Nash equilibrium. Güth and Hellwig (1986) and Mailath and Postlewaite (1990) have shown that reaching efficiency via a Bayes-Nash equilibrium is incompatible with voluntary participation.

${ }^{5}$ Our framewor $\mathrm{k}$ covers this model under the assumption that preferences are quasi-linear in privategoods consumption. This is a special case which has received considerable attention in the literature on optimal taxation, see e.g. Diamond (1998) and Saez (2001).

${ }^{6}$ Ledyard (2006) and Schmitz and Tröger (2012) study the conditions under which efficient outcomes can be implemented by means of a voting mechanism. Grüner and Koriyama (2012) study the conditions under which a majority of citizens would be in favor of replacing a voting procedure by a mechanism that guarantees an efficient outcome.
} 
we focus on a representative democracy. Citizens in our framework vote for politicians, and not over policies.

Lizzeri and Persico $(2001 ; 2004 ; 2005)$ and Roberson (2008) study political competition under the assumption that a policy proposal involves the provision of a public good and distribution of favors in the electorate. A key insight is that a policy that involves targeted transfers to special interests may win a majority against a policy that involves efficient public goods provision 7 These papers invoke the assumption that the benefits from public goods provision are common knowledge. Hence, there is no requirement of incentive compatibility. We will demonstrate in Section 3 that privacy of information makes i t more difficult to form a majority that votes against efficient public-goods provision.

Roberts (1977) and Meltzer and Richard (1981) are classics on the political economy of redistributive income taxation. These papers restricts attention to affine income tax schedules, so that preferences are single-peaked and the median voter theorem applies ${ }^{8}$ Röell (2012), and Brett and Weymark (2012) study the implications of the citizen-candidate-model (see Osborne and Slivinski, 1996; Besley and Coate, 1997) for Mirrleesian income taxation. Blomquist and Christiansen (1999) and Bierbrauer and Boyer (2013) study competition between vote-share-maximizing politicians in a simple Mirrlees-model with only two types of individuals, rich and poor 9 Finally, there is a literature on the political economy of taxation and public spending in dynamic models. A variety of political economy models has been explored by this literature 10 However, to the best of our knowledge, there is not yet an analysis of Downsian competition.

\section{An illustrative example}

We present a simple model in order to illustrate that political competition is more likely to generate efficient outcomes if individuals have private information on their preferences.

\footnotetext{
${ }^{7}$ The trade-off between efficiency and targetability is also present in Crutzen and Sahuguet (2009). They present a model of redistributive politics that extends those of Myerson (1993) and Lizzeri and Persico (2001) where raising taxes is distortionary due to an administrative cost of tax collection but give candidates the possibility to target some voters.

${ }^{8}$ Roemer (1999) and De Donder and Hindriks (2003) have characterized the outcomes of political competition under the assumption that income tax functions are quadratic.

${ }^{9}$ Blomquist and Christiansen (1999) study political support for a public provision of private goods. Bierbrauer and Boyer (2013) focus on the implications that differences in the competence of politicians have for the outcome of political competition.

${ }^{10}$ In Acemoglu, Golosov and Tsyvinski $(2008 ; 2010)$ political competition takes the form of a threat to be voted out of office, as in the political agency model by Barro (1973) and Ferejohn (1986). Battaglini and Coate (2008) study Ramsey taxation and public-goods provision in the context of the legislative bargaining model, see Baron and Ferejohn (1989). Fahri and Werning (2008) study political support for a taxation of capital income by making use of the probabilistic voting model due to Lindbeck and Weibull (1987). Martimort (2001) studies strategic budget deficits and optimal taxation in a model with partisan politics.
} 
For the purpose of the example, we make several simplifying assumptions that are going to be relaxed in later sections.

We assume that two politicians compete with each other and seek to win a majority. Politicians face a choice between two different types of platforms. They can either propose that an indivisible public good is provided and financed via equal cost-sharing, or they distribute favors in the electorate. The latter type of platform is modelled as a system of transfers that possibly depend on the intensity of an individual's preference for the public good. For now, we model this as a dichotomous policy choice, so that if the public good is provided all available resources have to be used to pay for it and nothing is left that could be used to finance transfers. This set up is borrowed from Lizzeri and Persico (2001).

There is a continuum of voters of measure 1 . Voter $i$ has a utility function $u_{i}=$ $q \theta_{i}+(1-q) c_{i}$, where $\theta_{i}$ is the voter's benefit from the public good, $q \in\{0,1\}$ indicates whether or not the public good is provided, and $c_{i}$ is the transfer received by voter $i$. We assume that there is a commonly known cross-section distribution of the public-goods preference $\theta_{i}$. This distribution is represented by a cumulative distribution function $F$, with bounded support $\Theta \subset \mathbb{R}_{+}$. Each voter has an initial endowment $e$ of a private consumption good. A system of transfers can be conveniently represented by a mapping $c: \Theta \rightarrow \mathbb{R}_{+}$that determines the individuals' private-goods consumption, i.e. whenever some individual $i$ has type $\theta$, then her private goods consumption equals $c(\theta)$, and the transfer is given by $c(\theta)-e$. We denote aggregate consumption by $E[c(\theta)]$. A system of transfers is resource-feasible provided that $E[c(\theta)] \leq e$.

We assume that the social surplus is higher if the public good is provided, i.e. $\theta_{m}>e$, where $\theta_{m}$ is the population average of the public-goods preference. We say that a political failure occurs if a politician who proposes this surplus-maximizing policy can be defeated by a politician who proposes a system of lump-sum-transfers.

Political failure under complete information. Suppose that politician 1 promises to provide the public good if he is elected. Suppose that politician 2 tries to defeat him with a system of transfers. The easiest way to do this is to target individuals with a low valuation of the public good: an individual with public goods preference $\theta_{i}$ has to be offered a consumption level of at least $\theta_{i}$ to be willing to vote for politician 2 . Hence, the votes of those with a low public-goods preference are cheap. To get a majority, all voters with a public goods preference below the median type, denoted by $\theta_{M}$, have to be attracted. The resource requirement of such a policy is

$$
\int_{0}^{\theta_{M}} \theta d F(\theta)=F\left(\theta_{M}\right) E\left[\theta \mid \theta \leq \theta_{M}\right]=\frac{1}{2} E\left[\theta \mid \theta \leq \theta_{M}\right]
$$

All other voters are offered a consumption level of zero. Consequently, this system of transfers is resource-feasible if $\frac{1}{2} E\left[\theta \mid \theta \leq \theta_{M}\right] \leq e$. Hence, a political failure occurs if

$$
\theta_{m}>e>\frac{1}{2} E\left[\theta \mid \theta \leq \theta_{M}\right]
$$


Political failure under private information. With private information on publicgoods preferences, transfers have to be incentive-compatible. In the given model, these incentive compatibility constraints take a very simple form: the transfer received by a voter must not depend on his public-goods preference. If there were $\theta$ and $\theta^{\prime}$ with $c(\theta)>c\left(\theta^{\prime}\right)$, then no individual would admit having a public-goods preference equal to $\theta^{\prime}$. Consequently, incentive compatibility holds if and only if there is a number $c_{m}$ so that, for all $\theta \in \Theta, c(\theta)=c_{m}$. The resource constraint requires that $c_{m}=e$.

A politician who proposes this transfer policy, wins against an opponent who offers the public good if and only if more than half of the electorate has a public-goods preference below $e$, i.e. if and only if $\theta_{M} \leq e$. Hence, under incomplete information a political failure occurs if

$$
\theta_{m}>e>\theta_{M}
$$

Proposition 1 If a political failure occurs with private information on preferences then it also occurs under complete information. The converse implication does not hold.

Proof To prove the first statement in the proposition, suppose that the inequalities in (2) hold. Since $\theta_{M}>\frac{1}{2} E\left[\theta \mid \theta \leq \theta_{M}\right]$, this implies that also the inequalities in (1) hold.

To prove the second statement in the proposition, note that political failures are impossible in the private information environment as soon as $F$ is a symmetric distribution which implies that $\theta_{m}=\theta_{M}$. However, the inequalities in (1) may hold with a symmetric distribution, e.g. if $F$ is a uniform distribution on the unit interval, and $e \in\left(\frac{1}{8}, \frac{1}{2}\right)$.

The proposition follows from the observation that, under complete information, transfers can be targeted to those who have a low valuation of the public good and therefore are easy to convince to vote against the public good. Consequently, the formation of a majority against the public good requires less resources than under private information on preferences.

\section{Publicly provided goods}

We begin with a framework in which a policy specifies the public provision and financing of a public or private good. In Section 6 we extend our analysis to a model of income taxation.

\subsection{The economic environment}

Preferences. We denote by $q_{i}$ person $i$ 's consumption of the publicly provided good. Individual $i$ 's valuation of the good is given by a function $v\left(\theta_{i}, q_{i}\right)$, i.e. where $\theta_{i}$ is referred to as person $i$ 's type. The set of types is denoted by $\Theta \subset \mathbb{R}_{+}$. We assume that $\Theta$ is either a 
compact interval, so that $\Theta=[\underline{\theta}, \bar{\theta}]$ or a finite subset of $[\underline{\theta}, \bar{\theta}]$ so that $\Theta=\left\{\theta_{1}, \theta_{2}, \ldots, \theta_{n}\right\}$, with $\theta_{1}=\underline{\theta}$ and $\theta_{n}=\bar{\theta}$.

The function $v$ is assumed to have the following properties. Zero consumption gives zero utility: for all $\theta_{i} \in \Theta, v\left(\theta_{i}, 0\right)=0$. The lowest type does not benefit from public goods provision: for all $q_{i}, v\left(\underline{\theta}, q_{i}\right)=0$. For all other types, the marginal benefit from increased consumption is positive and decreasing so that for all $\theta_{i}>\underline{\theta}$ and all $q_{i}, v_{2}\left(\theta_{i}, q_{i}\right)>0$ and $v_{22}\left(\theta_{i}, q_{i}\right) \leq 0$. The marginal benefit of consumption is increasing in the individual's type: for all $\theta \in(\underline{\theta}, \bar{\theta})$ and all $q>0, v_{12}\left(\theta_{i}, q_{i}\right)>0$.

Each individual privately observes his type. From an outsider's perspective, types of different voters are drawn independently and they are identically distributed. We denote by $f$ the probability mass or density function and by $F$ the cumulative distribution function. When we use an expectation operator in the following, then expectations are taken with respect to this distribution. We appeal to a law of large numbers for large economies ${ }^{11}$ so that we can also interpret $F$ as the empirical cross-section distribution of types.

Policies. A policy $p$ consists of a provision rule which determines an individual's consumption of the publicly provided good as a function of the individual's type, a rule that determines how an individual's private goods consumption depends on his type, and a distribution of transfers. These transfers enable policy-makers to make specific promises to subsets of the electorate. Formally, a policy is a triple $p=(q, c, G)$, where $q: \Theta \rightarrow \mathbb{R}_{+}$is the provision rule, $c: \Theta \rightarrow \mathbb{R}$ determines private goods consumption and $G: \mathbb{R}_{+} \rightarrow[0,1]$ is a $c d f$ which characterizes the distribution of transfers. Specifically, we follow Myerson (1993) and assume that the lump-sum transfers to different voters are iid random variables with probability distribution $G$. We appeal once more to the law of large numbers for large economies and interpret $G(x)$ not only as the probability that any one individual receives a transfer weakly smaller than $x$, but also as the population share of voters who receive such a transfer.

If individual $i$ receives a draw $x$ from the distribution $G$, then the individual's private goods consumption equals $x+c(\theta)$ if $\theta_{i}=\theta$. Hence, the draw $x$ from $G$ is a shifting parameter for the individual's consumption schedule $c$. Incentive compatibility, formally introduced below, will imply that individuals with higher types consume (weakly) more of the publicly provided good and therefore have to give up (weakly) more money. Consequently, $c$ will be a non-increasing function. We impose the normalization that $c(\bar{\theta})=0$. Combined with the assumption that the support of the distribution $G$ is bounded from below by 0 , this implies that non-negativity constraints on private goods consumption levels can be safely ignored in the following.

Given a policy $p=(q, c, G)$, we denote the utility level that is realized by an individual

\footnotetext{
${ }^{11}$ See Judd (1985), Feldman and Gilles (1985), Al-Najjar (2004), or Sun (2006).
} 
with type $\theta$ and a draw $x$ from the lottery by

$$
x+u(\theta \mid q, c)=x+c(\theta)+v(\theta, q(\theta)) .
$$

Admissible policies. Individuals have private information on their types, which implies that a policy has to satisfy the following incentive compatibility constraints: for all $\theta$ and $\theta^{\prime}$,

$$
v(\theta, q(\theta))+c(\theta) \geq v\left(\theta, q\left(\theta^{\prime}\right)\right)+c\left(\theta^{\prime}\right) .
$$

In addition, policies have to be feasible. Let $e$ be the economy's initial endowment with the private consumption good. We assume that $e$ is a large number. Feasibility holds provided that

$$
\int_{0}^{\infty} x d G(x)+E[c(\theta)]+K(q) \leq e .
$$

In addition, feasibility requires that, for each $\theta, q(\theta)$ belongs to a consumption set $\Lambda(q)$. We consider consumption sets that depend on the provision rule $q$. As explained below, this allows to cover both publicly provided private goods and pure public goods. We assume, for simplicity, that $\Lambda(q)$ is bounded from above, for all provision rules $q{ }^{12}$ The function $K$ gives the resource requirement of using provision rule $q$. We assume that the function $K$ is non-decreasing in $q(\theta)$, for all $\theta$, i.e. if the consumption of individuals of type $\theta$ goes up, while all other consumption levels remain constant, then the provision costs $K(q)$ cannot fall. This framework covers the following setups:

Pure public goods: With a good that is non-rival only $\bar{q}:=\max _{\theta \in \Theta} q(\theta)$ matters for the cost $K(q)$. We may therefore take $K(q)$ to be equal to $k(\bar{q})$, where $k$ is an increasing and convex cost function. If the good is non-excludable, then the consumption set $\Lambda(q)$ is such that $q(\theta) \in \Lambda(q)$ if and only if $q(\theta)=\bar{q}$, for all $\theta$.

Excludable public goods: An excludable public good has the same cost structure as a pure public good, but the consumption set changes due to excludability: $q(\theta) \in$ $\Lambda(q)$ if and only if $q(\theta) \in[0, \bar{q}]$, for all $\theta$.

Private goods: Private goods have the same consumption sets as excludable public goods but have a different cost structure because of rivalry. The cost is now increasing in aggregate consumption $E[q(\theta)]$ and we therefore take $K(q)$ to be equal to $k(E[q(\theta)])$.

When we work under the assumption that the set of types $\Theta$ is finite, we impose no further restrictions on the set of admissible policies. If we impose the assumption that $\Theta$ is a compact interval, we require in addition that the provision rule $q$ is continuously

\footnotetext{
${ }^{12}$ This assumption simplifies our proof. We conjecture that we could also use the economy's resource constraint to show that any admissible policy gives rise to bounded consumption levels.
} 
differentiable. This is a technical assumption that facilitates the characterization of admissible policies which is a main step in the proof of our main result. If we imposed additional assumptions on the utility function $v$, our characterization would apply even without this restriction 13 The assumptions introduced in this paragraph will be imposed in the following without further mention.

Surplus-maximization. We say that an admissible policy is surplus-maximizing or first-best if the budget constraint in (3) holds as an equality and the provision-rule $q$ is chosen so as to maximize

$$
S(q):=E[v(\theta, q(\theta))]-K(q)
$$

We denote the surplus-maximizing provision rule by $q^{*}$. We say that a policy $p=(q, c, G)$ is surplus-maximizing if (3) holds as an equality and $q=q^{*}$.

Welfare. An admissible policy $p=(q, c, G)$ confronts individuals with a randomized mechanism. We denote by

$$
U(\theta \mid p):=\int_{0}^{\infty} \Phi(x+c(\theta)+v(\theta, q(\theta))) d G(x),
$$

the expected utility that an individual with type $\theta$ realizes under such a policy. The function $\Phi$ is assumed to be concave and increasing, so as to capture the risk attitudes of individuals. If the function $\Phi$ is strictly concave, then individuals are risk-averse. If $\Phi$ is linear, then individuals are risk-neutral. To compute the welfare induced by a policy $p$, we use a welfare function

$$
W(p)=E[\gamma(\theta) U(\theta \mid p)]
$$

where $\gamma: \Theta \rightarrow \mathbb{R}_{+}$is a function that specifies the welfare weights for different types of individuals. We denote the set of welfare-maximizing policies by $P^{W}$, i.e. $p \in P^{W}$ if there exists a function $\gamma$ so that $p$ maximizes $E[\gamma(\theta) U(\theta \mid p)]$ over the set of admissible policies.

\subsection{Political competition}

There are two politicians. A policy for politician $j \in\{1,2\}$, is an admissible triple $p^{j}=\left(q^{j}, c^{j}, G^{j}\right)$. We assume that the two politicians choose policies simultaneously and independently. In particular, transfers are also drawn simultaneously and independently. This implies that politician 1 cannot see the transfers offered by politician 2 and then generate a majority by offering less too a tiny group of voters and offering more to anybody else.

\footnotetext{
${ }^{13}$ Specifically, we would have to assume that $v(\theta, q(\theta))=\theta \bar{v}(q(\theta))$, for some increasing and concave function $\bar{v}$.
} 
Voters observe the transfers offered to them by the two politicians and then caste their vote, i.e. voter $i$ observes, for each politician $j$, the provision rule $q^{j}$, the consumption rule $c^{j}$ and his drawing from the distribution $G^{j}$, henceforth denoted by $x_{i}^{j}{ }_{14}^{14}$ Voter $i$ votes for politician 1 if $u\left(\theta_{i} \mid q^{1}, c^{1}\right)+x_{i}^{1}>u\left(\theta_{i} \mid q^{2}, c^{2}\right)+x_{i}^{2}$, tosses a coin if these expressions are equal, and votes for politician 2 otherwise. If the distributions $G^{1}$ and $G^{2}$ are atomless, the probability that any one voter $i$ votes for politician 1 is given by

$$
\Pi^{1}\left(p^{1}, p^{2}\right):=E\left[\int_{\mathbb{R}_{+}} G^{2}\left(x_{i}^{1}+u\left(\theta_{i} \mid q^{1}, c^{1}\right)-u\left(\theta_{i} \mid q^{2}, c^{2}\right)\right) d G^{1}\left(x_{i}^{1}\right)\right]
$$

By the law of large numbers, we can also interpret $\Pi^{1}\left(p^{1}, p^{2}\right)$ as politician 1's vote share and $\Pi^{2}\left(p^{1}, p^{2}\right)=1-\Pi^{1}\left(p^{1}, p^{2}\right)$ as politician 2 's vote share.

Definition 1 Two policies $p_{e q}^{1}$ and $p_{e q}^{2}$ are a Nash equilibrium if $\Pi^{1}\left(p_{e q}^{1}, p_{e q}^{2}\right) \geq \Pi^{1}\left(p^{1}, p_{e q}^{2}\right)$, for every admissible $p^{1}$, and $\Pi^{2}\left(p_{\text {eq }}^{1}, p_{\text {eq }}^{2}\right) \geq \Pi^{2}\left(p_{\text {eq }}^{1}, p^{2}\right)$, for every admissible $p^{2}$.

Our definition focuses on equilibria in pure strategies, i.e. we do not consider the possibility that politicians randomize over various admissible policies. Equilibrium existence can therefore not be guaranteed with an appeal to standard results 15 We provide conditions for the existence of pure strategy equilibria in Section 7 below.

\subsection{The main results}

The following two theorems state our main results. We provide a complete equilibrium characterization in Section 4.4. Proofs are in Section 5.

Theorem 1 If the set of Nash equilibria is non-empty, then there is one and only one symmetric Nash equilibrium. In this equilibrium, policies are surplus-maximizing.

Theorem 2 Suppose that individuals are risk averse. There is a surplus-maximizing policy $p^{*}$ so that $\Pi^{1}\left(p^{*}, p^{W}\right) \geq \frac{1}{2}$ for all $p^{W} \in P^{W}$. Moreover, the inequality is strict whenever $p^{W}$ is not surplus-maximizing.

Theorem 1 can be viewed as a first welfare theorem for the given model of political competition. Provided that there is an equilibrium at all, there is also an equilibrium that is surplus-maximizing and therefore ex-post efficient. Due to the assumption that preferences are quasi-linear, the setup is of course more restrictive than the one in which the first welfare theorem for competitive equilibrium allocations holds. Still, it is intriguing to note that the first welfare theorem for competitive equilibrium allocations no longer

\footnotetext{
${ }^{14}$ Note that risk attitudes play no role for the characterization of voting behavior because individuals caste their votes after having seen their outcomes from the politicians' lotteries.

${ }^{15}$ If we allowed for mixed strategy equilibria we could ensure that strategy spaces are compact by first discretizing the set of admissible policies and then assume that politicians randomize over this discrete set.
} 
applies if there are public goods or externalities. Theorem 1, by contrast, applies irrespectively of whether the publicly provided goods are private or not. Hence, in the given model, governments outperform markets: political competition generates Pareto-efficient outcomes in all circumstances, whereas competitive markets generate Pareto-efficient outcomes only if the goods involved are private. This positive assessment, however, depends on the assumption that the only policy goal is to get an ex-post efficient outcome. If the policy goal is to maximize welfare, then, Theorem 2 tells us that this is incompatible with a political equilibrium.

Theorem 2 shows that there is a surplus-maximizing policy that defeats any welfaremaximizing one, i.e. a politician who knows that his opponent runs on some welfaremaximizing platform, can make sure that he will not be defeated. Thus, the only Paretoefficient outcome that is compatible with a political equilibrium is the surplus-maximizing one. Theorem 2 comes as a surprise if one starts out with the basic intuition that the vote share that is generated by a welfare-maximizing policy should depend on the distribution of types. For a pure public-goods application, suppose that the distribution $F$ is such that more than half of the electorate has type $\underline{\theta}$. Hence, there is a majority of voters that do not value the public good at all. Now suppose a politician proposes a policy that maximizes a welfare-function that assigns a positive weight only to this group of individuals. As follows from our proof, a politician who targets this big group with a low public-goods preference will lose against a politician who proposes the surplus-maximizing quantity in combination with transfers. The latter will win a certain fraction of the voters in the majority group because of the transfers he offers to them, and, in addition, he will get the vot es of the minority group. The overall effect is that he will win more than fifty percent of the votes. This policy is successful only because voters have private information on their preferences. This forces a politician who targets the big group to respect incentive compatibility constraints. This makes it difficult to channel resources to the big group only. If the deal for the big group becomes too good, incentive compatibility fails because individuals from the small group will declare that they also belong to the big group.

Appendix A.3 contains an extension of Theorem 1 to an economy with finitely many individuals. A finite number gives rise to one additional complication: the cross-section distribution of types is no longer known, but a random quantity. Policies therefore have to deal with a problem of information aggregation. To be specific, consider the case of a pure public good. In a model with a continuum of individuals, the surplus-maximizing quantity

$$
\max _{q \in \mathbb{R}_{+}} E[v(\theta, q)]-k(q)
$$

is known a priori by the law of large numbers. In a finite economy, however, the number of people who value it highly is a random quantity so that a policy maker has to communicate with individuals in order to learn the vector of types and to be able to compute the value 
of

$$
\max _{q \in \mathbb{R}_{+}} \frac{1}{n}\left(\sum_{i=1}^{n} v\left(\theta_{i}, q\right)-k(q)\right) .
$$

In such a setting each individual is pivotal in the sense that her communication has an influence on the optimal public-goods provision level. However, as we show in Appendix A.3. there is an extension of our main results to an economy with finitely many individuals.

\subsection{Equilibrium characterization}

In the following, Corollary 1 provides the equilibrium characterization for a model with a continuum of types and Corollary 2 contains the characterization for a discrete set of types. The Corollaries follow from the proofs of Theorem 1 in Section 5 and Appendix A.1. We also comment on why we need separate proofs for these two cases and provide an intuition for our equilibrium characterization.

Corollary 1 Suppose that $\Theta=[\underline{\theta}, \bar{\theta}]$. If the set of equilibria is non-empty, then the unique symmetric equilibrium $p_{e q}=\left(q_{e q}, c_{e q}, G_{e q}\right)$ is such that:

(a) The provision rule is surplus-maximizing $q_{e q}=q^{*}$.

(b) Private goods consumption is such that for any $\theta \in \Theta$,

$$
c_{e q}(\theta)=v\left(\bar{\theta}, q^{*}(\bar{\theta})\right)-v\left(\theta, q^{*}(\theta)\right)-\int_{\theta}^{\bar{\theta}} v_{1}\left(s, q^{*}(s)\right) d s,
$$

(c) $G_{e q}$ is uniform on $\left[0,2\left(e+S_{v}\left(q^{*}\right)\right)\right]$, where

$$
S_{v}\left(q^{*}\right):=S\left(q^{*}\right)-\left\{v\left(\bar{\theta}, q^{*}(\bar{\theta})\right)-E\left[\frac{F(\theta)}{f(\theta)} v_{1}\left(\theta, q^{*}(\theta)\right)\right]\right\} .
$$

The proof combines insights from the analysis of constant-sum games, see e.g. Osborne and Rubinstein (1994), the equilibrium analysis of the divide-the-dollar-game by Myerson (1993), and the typical characterization of incentive compatible outcomes in models with quasi-linear preferences and a continuum of types, which can, for instance, be found in Mas-Colell, Whinston and Green (1995) and Milgrom and Segal (2002). With a continuum of types, the requirement of incentive-compatibility reduces the dimensionality of the policy space in a very convenient way. The envelope theorem implies that $u^{\prime}(\theta \mid q, c)=v_{1}(\theta, q(\theta))$. Hence,

$$
\begin{aligned}
u(\theta \mid q, c) & =u(\bar{\theta} \mid q, c)-\int_{\theta}^{\bar{\theta}} u^{\prime}(s \mid q, c) d s \\
& =v(\bar{\theta}, q(\bar{\theta}))-\int_{\theta}^{\bar{\theta}} v_{1}(s, q(s)) d s,
\end{aligned}
$$


and therefore

$$
\begin{aligned}
c(\theta) & =u(\theta \mid q, c)-v(\theta, q(\theta)) \\
& =v(\bar{\theta}, q(\bar{\theta}))-\int_{\theta}^{\bar{\theta}} v_{1}(s, q(s)) d s-v(\theta, q(\theta)) .
\end{aligned}
$$

Consequently, if the provision function $q$ is given, there is no longer a degree of freedom in the choice of the $c$-function. This simplification is not available if the set of types is discrete. With a discrete set of types, for any given pair $(q, G)$ there are many $c$-functions with the property that the triple $(q, c, G)$ is incentive compatibility. A separate step in the proof therefore is to show which $c$-function emerges in equilibrium. As we show in Appendix A.1, if equilibrium existence is ensured, then there is an equilibrium in which $c_{e q}$ has the following property: given $\left(q_{e q}, G_{e q}\right)$, it yields the lowest value of $E[c(\theta)]$ in the set of $c$-functions with the property that $\left(q_{e q}, c, G_{e q}\right)$ is incentive-compatible. This implies that all local upward incentive constraints hold as an equality, i.e. for any one $\theta_{l}<\bar{\theta}$,

$$
c_{e q}\left(\theta_{l}\right)+v\left(\theta_{l}, q_{e q}\left(\theta_{l}\right)\right)=c_{e q}\left(\theta_{l+1}\right)+v\left(\theta_{l}, q_{e q}\left(\theta_{l+1}\right)\right) .
$$

The logic is as follows. By incentive compatibility, higher types consume more of the publicly provided good and less of the private good. Therefore, minimal private goods consumption is achieved if any one individual's private goods consumption is chosen as close as possible to the consumption level of the next higher type. This insight yields the following equilibrium characterization for the model with a discrete set of types.

Corollary 2 Suppose that the set of types is discrete. If an equilibrium exists, then the unique symmetric equilibrium $p_{e q}=\left(q_{e q}, c_{e q}, G_{e q}\right)$ is such that:

(a) The provision rule is surplus-maximizing $q_{e q}=q^{*}$.

(b) Private goods consumption is such that that $c_{e q}(\bar{\theta})=0$ and for any $\theta_{l}<\bar{\theta}$,

$$
\begin{aligned}
c_{e q}\left(\theta_{l}\right)= & v\left(\bar{\theta}, q^{*}(\bar{\theta})\right)-v\left(\theta_{l}, q^{*}\left(\theta_{l}\right)\right) \\
& -\sum_{k=l}^{n-1}\left\{v\left(\theta_{k+1}, q^{*}\left(\theta_{k+1}\right)\right)-v\left(\theta_{k}, q^{*}\left(\theta_{k+1}\right)\right)\right\},
\end{aligned}
$$

(c) $G_{e q}$ is uniform on $\left[0,2\left(e+S_{v}\left(q^{*}\right)\right)\right]$, where

$$
\begin{aligned}
S_{v}\left(q^{*}\right):= & S\left(q^{*}\right)-\left\{v\left(\bar{\theta}, q^{*}(\bar{\theta})\right)\right. \\
& -\sum_{k=1}^{n-1} f\left(\theta_{k}\right) \frac{F\left(\theta_{k}\right)}{f\left(\theta_{k}\right)}\left\{v\left(\theta_{k+1}, q^{*}\left(\theta_{k+1}\right)\right)-v\left(\theta_{k}, q^{*}\left(\theta_{k+1}\right)\right)\right\} .
\end{aligned}
$$

It is instructive to relate Corollaries 1 and 2 to the analysis of Myerson (1993). Myerson looks at a divide-the-dollar-game: the economy has an endowment of $e$ dollars. A policy specifies which voter receives how many dollars. There are no public goods and there is complete information on preferences, every voter simply wants to receive as many dollars as possible. Myerson shows that the unique symmetric equilibrium is such that the offer 
to any one voter is a random draw from a uniform distribution with support $[0,2 e]$. With an appeal to the law of large numbers, this probability distribution is then interpreted as a cross-section distribution of transfers to different voters. Thus, the equilibrium analysis reveals that politicians have an incentive to "cultivate favored minorities": some voters are treated very well and others are treated very badly. The same force is at play in our equilibrium: the resources that are left after th e surplus-maximizing provision level is paid for are allocated in exactly the same way as in Myerson's analysis.

However, and in contrast to Myerson (1993), a policy in our case also involves a decision on how many resources to devote to the publicly provided good. The amount that is available for pork-barrel spending is then an endogenous quantity and given by $e+S_{v}(q)$. Moreover, equilibrium behavior is such that politicians do not maximize the amount that is available for pork-barrel spending. This would require to maximize the virtual surplus $S_{v}(q)$, as opposed to the "true" surplus $S(q)$, and yield a provision rule $q_{v}$ that is distorted downwards, i.e. $q_{v}(\theta) \leq q^{*}(\theta)$, for all $\theta$, with a strict inequality whenever $\theta<\bar{\theta}$. Now, what is the force that prevents politician's from maximal porkbarrel-spending? There are two ways to convince a voter to support a policy proposal, one can offer transfers and one can offer utility derived from a publicly provided good. Our equilibrium analysis reveals that it does not payoff to reduce the prov ision level below the first-best level so as to be able to offer more transfers. The loss of political support due to the reduced provision level is not compensated for by the increase of political support that comes with increased pork-barrel spending.

\section{Proofs of the main results}

We provide different proofs for the case in which $\Theta$ is a compact interval and the case in which $\Theta$ is a finite ordered set. The discrete case is dealt with in Appendix A.1. Here, we present the proof for a continuum of types.

Characterization of admissible policies. The following Lemma provides a characterization of admissible policies. It is based on standard arguments, in particular on the characterization of incentive compatible policies and their budgetary implications - see, for instance, Mas-Colell, Whinston and Green (1995) and Milgrom and Segal (2002). We therefore state it without proof.

Lemma 1 Suppose that $q$ is a continuously differentiable function. Then, a policy $p=$ $(q, c, G)$ is admissible if and only if it satisfies the following constraints:

(i) Monotonicity: $q$ is a non-decreasing function.

(ii) Utility: for all $\theta$,

$$
c(\theta)+v(\theta, q(\theta))=v(\bar{\theta}, q(\bar{\theta}))-\int_{\theta}^{\bar{\theta}} v_{1}(s, q(s)) d s .
$$


(iii) Resource constraint:

$$
\int_{0}^{\infty} x d G(x) \leq e+S_{v}(q)
$$

where

$$
S_{v}(q):=E[v(\theta, q(\theta))]-K(q)-\left(v(\bar{\theta}, q(\bar{\theta}))-E\left[\frac{F(\theta)}{f(\theta)} v_{1}(\theta, q(\theta))\right]\right) .
$$

(iv) For each $\theta, q(\theta) \in \Lambda(q)$.

The incentive compatibility constraints imply that individuals with higher types can realize an information rent. The information rent of a type $\theta$-individual is given by the expression $v(\bar{\theta}, q(\bar{\theta}))-\int_{\theta}^{\bar{\theta}} v_{1}(s, q(s)) d s$ in equation $(9)$. These information rents reduce the resources that are available for private goods consumption. The expected value of the information rent is given by

$$
E\left[v(\bar{\theta}, q(\bar{\theta}))-\int_{\theta}^{\bar{\theta}} v_{1}(s, q(s)) d s\right]=v(\bar{\theta}, q(\bar{\theta}))-E\left[\frac{F(\theta)}{f(\theta)} v_{1}(\theta, q(\theta))\right] .
$$

An inspection of equations (10), 11) and (12) reveals that the expected information rent implies that the upper bound on pork-barrel spending is the virtual surplus $S_{v}(q)$, as opposed to the (non-virtual) surplus $S(q)$.

The characterization in Lemma 1 implies that an admissible policy $p=(q, c, G)$ can be completely characterized by the provision rule $q$ and the distribution function $G$. To see this, note that equation (9) implies that

$$
c(\theta)=v(\bar{\theta}, q(\bar{\theta}))-v(\theta, q(\theta))-\int_{\theta}^{\bar{\theta}} v_{1}(s, q(s)) d s,
$$

so that the function $c$ can be derived from (13) if $q$ is given. In the following, we will therefore represent an admissible policy as a pair $p=(q, G)$ that satisfies conditions (i)(iv) in Lemma 1, with the understanding that the corresponding $c$-function then follows from (13).

Vote-Shares. Upon using equation (9), the probability that any one voter $i$ votes for politician 1 is equal to the probability of the event

$$
x_{i}^{2} \leq x_{i}^{1}+v\left(\bar{\theta}, q^{1}(\bar{\theta})\right)-\int_{\theta}^{\bar{\theta}} v_{1}\left(s, q^{1}(s)\right) d s-v\left(\bar{\theta}, q^{2}(\bar{\theta})\right)+\int_{\theta}^{\bar{\theta}} v_{1}\left(s, q^{2}(s)\right) d s .
$$

If the distributions $G^{1}$ and $G^{2}$ are atomless the vote share of politician 1 can be written as

$$
\Pi^{1}\left(p^{1}, p^{2}\right):=E\left[\int_{\mathbb{R}_{+}} G^{2}\left(x_{i}^{1}+h\left(\theta, q^{1}\right)-h\left(\theta, q^{2}\right)\right) d G^{1}\left(x_{i}^{1}\right)\right]
$$

where

$$
h\left(\theta, q^{j}\right):=v\left(\bar{\theta}, q^{j}(\bar{\theta})\right)-\int_{\theta}^{\bar{\theta}} v_{1}\left(s, q^{j}(s)\right) d s,
$$




\subsection{Proof of Theorem 1}

The proof of Theorem 1 follows from the sequence of Lemmas below.

Lemma 2 If the set of equilibria is non-empty, then there exists a symmetric equilibrium.

Proof The game of political competition is a symmetric constant-sum game. For the properties of such games, see e.g. Osborne and Rubinstein (1994). Now suppose that there is an equilibrium in which politician 1 proposes a policy $p_{e q}$. For a constant sumgame it holds that $p_{e q}$ is an equilibrium policy if and only if

$$
p_{e q} \in \operatorname{argmin}_{p^{1} \in P} \max _{p^{2} \in P} \Pi^{2}\left(p^{1}, p^{2}\right),
$$

where $P$ is the set of admissible policies. Since the game is symmetric, if $p_{e q}$ solves this problem, then it is also the case that

$$
p_{e q} \in \operatorname{argmin}_{p^{2} \in P} \max _{p^{1} \in P} \Pi^{1}\left(p^{1}, p^{2}\right) .
$$

Hence, $\left(p_{e q}, p_{e q}\right)$ is a symmetric Nash-equilibrium.

Lemma 3 Suppose that there is a symmetric equilibrium. Denote by $q_{e q}$ the corresponding provision rule. Then, the equilibrium distribution of lump-sum transfers is a uniform distribution on $\left[0,2\left(e+S_{v}\left(q_{e q}\right)\right)\right]$.

Proof If a symmetric equilibrium exists, then it has to be the case that any one politician $j$ choose the distribution $G^{j}$ so as to maximize his vote share conditional on $q^{1}=q^{2}=q_{e q}$. Otherwise he could increase his vote share by sticking to the provision rule $q_{e q}$, but offering a different distribution of lump-sum transfers. Conditional on $q^{1}=q^{2}=q_{e q}$, the vote share of politician 1 in (17) becomes

$$
\Pi^{1}\left(p^{1}, p^{2}\right)=\int_{\mathbb{R}_{+}} G^{2}\left(x_{i}^{1}\right) d G^{1}\left(x_{i}^{1}\right) .
$$

Given $G^{2}$, he chooses $G^{1}$ so as to maximize this expression subject to the constraint that $\int_{0}^{\infty} x_{i}^{1} d G^{1}\left(x_{i}^{1}\right) \leq e+S_{v}\left(q_{e q}\right)$. Politician 2 solves the analogous problem. Hence, conditional on $q^{1}=q^{2}=q_{e q}, G^{1}$ has to be a best response to $G^{2}$ and vice versa. This problem has been analyzed in Theorem 1 of Myerson (1993), who shows that there is a unique pair of functions $G^{1}$ and $G^{2}$ which satisfy these best response requirements and the symmetry requirement $G^{1}=G^{2}$. Accordingly, $G^{1}$ and $G^{2}$ both have to be uniform distributions on $\left[0,2\left(e+S_{v}\left(q_{e q}\right)\right)\right]$.

Lemma 4 Let $q_{\text {eq }}$ be a provision rule which is part of a symmetric Nash equilibrium. Let $G_{q_{e q}}^{u}$ be a uniform distributions on $\left[0,2\left(e+S_{v}\left(q_{e q}\right)\right)\right]$. Let $G_{q_{e q}}^{d}$ be a degenerate distribution which puts unit mass on $e+S_{v}\left(q_{e q}\right)$. If $p^{1}=\left(q_{e q}, G_{q_{e q}}^{u}\right)$ is a best response for politician 
1 against $p^{2}=\left(q_{e q}, G_{q_{e q}}^{u}\right)$. Then $\bar{p}^{1}=\left(q_{e q}, G_{q_{e q}}^{d}\right)$ is also a best response against $p^{2}=$ $\left(q_{e q}, G_{q_{e q}}^{u}\right)$.

Proof If $p^{1}=\left(q_{e q}, G_{q_{e q}}^{u}\right)$ is a best response for politician 1 against $p^{2}=\left(q_{e q}, G_{q_{e q}}^{u}\right)$, then it yields a vote share of $\frac{1}{2}$ since the game is symmetric. Upon evaluating the expression in (16) under the assumption that $G^{2}=G^{u}$ and $G^{1}=G_{q_{e q}}^{d}$, one verifies that $\bar{p}^{1}=\left(q_{e q}, G_{q_{e q}}^{d}\right)$ does also generate a vote share of $\frac{1}{2}$.

Lemma 5 If $q_{e q}$ is the provision rule which is part of a symmetric Nash equilibrium, then it is equal to the surplus-maximizing provision rule, i.e. $q_{e q}=q^{*}$.

Proof The following observation is an implication of Lemmas 3 and 4 . If $q_{e q}$ is part of a symmetric Nash equilibrium, then it has to solve the following constrained best response problem of politician 1: choose a provision rule $q^{1}$ so as to maximize

$$
\Pi^{1}=E\left[\int_{\mathbb{R}_{+}} G^{2}\left(x_{i}^{1}+h\left(\theta, q^{1}\right)-h\left(\theta, q^{2}\right)\right) d G^{1}\left(x_{i}^{1}\right)\right]
$$

subject to the following constraints: $G^{1}=G_{q^{1}}^{d}, q^{2}=q_{e q}$, and $G^{2}=G_{q_{e q}}^{u}$. Otherwise, politician 1 could improve upon his equilibrium payoff by deviating from $q_{e q}$, which would be a contradiction to $q_{e q}$ being part of an equilibrium.

We now characterize the solution to the constrained best-response problem. The problem can equivalently be stated as follows: choose $q^{1}$ so as to maximize

$$
\Pi^{1}=E\left[G_{q_{e q}}^{u}\left(e+S_{v}\left(q^{1}\right)+h\left(\theta, q^{1}\right)-h\left(\theta, q_{e q}\right)\right)\right] .
$$

The assumption that admissible provision rules have to be bounded, in combination with the assumption that $e$ is sufficiently large implies that, for all $q^{1}$ and for all $\theta \in \Theta$,

$$
e+S_{v}\left(q^{1}\right)+h\left(\theta, q^{1}\right)-h\left(\theta, q_{e q}\right)>0 .
$$

It also implies that, for all $q^{1}$ and for all $\theta \in \Theta$,

$$
e+S_{v}\left(q^{1}\right)+h\left(\theta, q^{1}\right)-h\left(\theta, q_{e q}\right)<2\left(e+S_{v}\left(q_{e q}\right)\right) .
$$

Hence, for all $\theta$,

$$
G_{q_{e q}}^{u}\left(e+S_{v}\left(q^{1}\right)+h\left(\theta, q^{1}\right)-h\left(\theta, q_{e q}\right)\right)=\frac{e+S_{v}\left(q^{1}\right)+h\left(\theta, q^{1}\right)-h\left(\theta, q_{e q}\right)}{2\left(e+S_{v}\left(q_{e q}\right)\right)},
$$

so that the objective in 18 becomes

$$
\begin{aligned}
\Pi^{1} & =E\left[\frac{e+S_{v}\left(q^{1}\right)+h\left(\theta, q^{1}\right)-h\left(\theta, q_{e q}\right)}{2\left(e+S_{v}\left(q_{e q}\right)\right)}\right] \\
& =\frac{e+S_{v}\left(q^{1}\right)+E\left[h\left(\theta, q^{1}\right)\right]-E\left[h\left(\theta, q_{e q}\right)\right]}{2\left(e+S_{v}\left(q_{e q}\right)\right)}
\end{aligned}
$$


By equations (12) and (15), we have that

$$
E\left[h\left(\theta, q^{1}\right)\right]=v(\bar{\theta}, q(\bar{\theta}))-E\left[\frac{F(\theta)}{f(\theta)} v_{1}(\theta, q(\theta))\right] .
$$

Upon using equation (11), we find that

$$
S_{v}\left(q^{1}\right)+E\left[h\left(\theta, q^{1}\right)\right]=E[v(\theta, q(\theta))]-K(q)=S\left(q^{1}\right) .
$$

Upon substituting this into $(19)$, we obtain

$$
\Pi^{1}=\frac{e+S\left(q^{1}\right)-E\left[h\left(\theta, q_{e q}\right)\right]}{2\left(e+S_{v}\left(q_{e q}\right)\right)} .
$$

Consequently, politician 1 chooses $q^{1}$ so as to maximize the surplus $S\left(q^{1}\right)$, which yields $q=q^{*}$.

\subsection{Proof of Theorem 2}

Let $W$ be a given welfare function. Upon using the characterization of admissible policies in Lemma 1, the welfare that is induced by an admissible policy $p=(q, G)$ is given by

$$
W(p)=E\left[\gamma(\theta) \int_{0}^{\infty} \Phi\left(x+v(\bar{\theta}, q(\bar{\theta}))-\int_{\theta}^{\bar{\theta}} v_{1}(s, q(s)) d s\right) d G(x)\right] .
$$

Under a welfare-maximizing policy $q$ and $G$ are chosen so as to maximize this expression subject to the constraints that (i) $q$ is a non-decreasing function, (ii) that, for all $\theta, q(\theta) \in$ $\Lambda(q)$, and (iii) that the resource constraint holds as an equality, i.e. that $\int_{0}^{\infty} x d G(x)=$ $e+S_{v}(q)$. Now, suppose that individuals are risk averse. Then the function $\Phi$ is strictly concave, so that, by Jensen's inequality,

$$
\begin{aligned}
& E\left[\gamma(\theta) \int_{0}^{\infty} \Phi\left(x+v(\bar{\theta}, q(\bar{\theta}))-\int_{\theta}^{\bar{\theta}} v_{1}(s, q(s)) d s\right) d G(x)\right] \\
& <E\left[\gamma(\theta) \Phi\left(e+S_{v}(q)+v(\bar{\theta}, q(\bar{\theta}))-\int_{\theta}^{\bar{\theta}} v_{1}(s, q(s)) d s\right)\right],
\end{aligned}
$$

for any non-degenerate distribution $G$, and any given provision rule $q$. Hence, a welfaremaximizing policy consists of a degenerate distribution $G_{q}^{d}$ which puts unit mass on $e+S_{v}(q)$ and a provision rule $q$ which maximizes

$$
E\left[\gamma(\theta) \Phi\left(e+S_{v}(q)+v(\bar{\theta}, q(\bar{\theta}))-\int_{\theta}^{\bar{\theta}} v_{1}(s, q(s)) d s\right)\right]
$$

subject to the constraints that $q$ is a non-decreasing function and that, for all $\theta, q(\theta) \in$ $\Lambda(q)$. We will denote such a policy henceforth by $p^{W}=\left(q^{W}, G_{q^{W}}^{d}\right)$. Now consider a policy $p^{*}=\left(q^{*}, G^{*}\right)$, where $q^{*}$ is the surplus-maximizing provision rule and $G^{*}$ is a 
uniform distribution on $\left[0,2\left(e+S_{v}\left(q^{*}\right)\right)\right]$. We will now show that $\Pi^{1}\left(p^{W}, p^{*}\right) \leq \frac{1}{2}$, with a strict inequality whenever $q^{W} \neq q^{*}$. By the arguments in the proof of Lemma 5 ,

$$
\begin{aligned}
\Pi^{1}\left(p^{W}, p^{*}\right) & =\frac{e+S\left(q^{W}\right)-E\left[h\left(\theta, q^{*}\right)\right]}{2\left(e+S_{v}\left(q^{*}\right)\right)} \\
& \leq \frac{e+S\left(q^{*}\right)-E\left[h\left(\theta, q^{*}\right)\right]}{2\left(e+S_{v}\left(q^{*}\right)\right)} \\
& =\frac{e+S_{v}\left(q^{*}\right)}{2\left(e+S_{v}\left(q^{*}\right)\right)} \\
& =\frac{1}{2}
\end{aligned}
$$

where the inequality in the second line is strict whenever $q^{W} \neq q^{*}$ and the equality in the third line follows from equations (11), (12) and $(15)$.

\section{Income taxation}

In this section we extend the analysis to a Mirrleesian model of income taxation, under the maintained assumption that preferences are quasi-linear in private goods consumption.

\subsection{The economic environment}

Preferences. Voter $i$ 's utility function is given by $u_{i}=c_{i}-\tilde{v}\left(\omega_{i}, y_{i}\right)$. As before, $c_{i}$ denotes the voter's consumption of private goods. The voter's contribution to the economy's output is denoted by $y_{i}$. The literature on income taxation refers to $c_{i}$ also as $i$ 's after-tax-income and to $y_{i}$ as $i$ 's pre-tax-income. The function $\tilde{v}$ captures the utility cost of productive effort. This cost depends on how much output is generated and on the individual's type $\omega_{i}$, which belongs to a set of types $\Omega$ which is either a compact interval so that $\Omega=[\underline{\omega}, \bar{\omega}]$, or a finite ordered set so that $\Omega=\left\{\omega_{1}, \ldots, \omega_{n}\right\}$, with $\omega_{1}=\underline{\omega}$ and $\omega_{n}=\bar{\omega}$. We assume that the cost function is increasing and convex in the level of output so that $\tilde{v}_{2}\left(\omega_{i}, y_{i}\right)>0$ and $\tilde{v}_{22}\left(\omega_{i}, y_{i}\right)>0$, for all $\omega_{i} \in W$ and all $y_{i}>0$. Costs are zero if no output is generated, so that $\tilde{v}\left(\omega_{i}, 0\right)=0$, for all $\omega_{i}$. Higher types have lower absolute and marginal effort costs, i.e. $\tilde{v}_{1}\left(\omega_{i}, y_{i}\right)<0$, and $\tilde{v}_{12}\left(\omega_{i}, y_{i}\right)<0$, for all $\omega_{i} \in(\underline{\omega}, \bar{\omega})$ and all $y_{i}>0 .{ }^{16}$ Finally, the Inada conditions hold: for all $\omega_{i} \in W, \lim _{y_{i} \rightarrow 0} v_{2}\left(\omega_{i}, y_{i}\right)=0$, and $\lim _{y_{i} \rightarrow \infty} v_{2}\left(\omega_{i}, y_{i}\right)=\infty$. Any one individual's skill type $\omega_{i}$ is taken to be a random variable with a cumulative distribution function $F$ and a continuous density $f$.

\footnotetext{
${ }^{16}$ In the literature, one often finds additional assumptions which are not needed for our purposes. Specifically, the function $v$ is often derived as follows: it is assumed that there is a disutility $\tilde{v}\left(h_{i}\right)$ of having to work $h_{i}$ hours. This disutility is assumed to be the same for all individuals. By contrast, individuals differ in their hourly wages. Hence, if an individual with wage $\omega_{i}$ wants to achieve an income of $y_{i}$ she has to work for $\frac{y_{i}}{\omega_{i}}$ hours and this comes with a utility cost equal to $\tilde{v}\left(\frac{y_{i}}{\omega_{i}}\right)$.
} 
Policies. A policy $p=(c, y, G)$ consists of (i) a function $c: \Omega \rightarrow \mathbb{R}_{+}$which determines any one individual's private goods consumption as a function of the individual's type, (ii) a function $y: \Omega \rightarrow \mathbb{R}_{+}$which determines the individual's contribution to the economy's output and (iii) a cross-section distribution of lump-sum-transfers $G$. If individual $i$ receives a draw $x$ from the distribution $G$, then the individual's private goods consumption equals $x$ in the event that $\omega_{i}=\underline{\omega}$ and equals $x+c(\omega)$ if $\omega_{i}=w$. In the income tax model, incentive compatibility will imply that individuals with higher types provide (weakly) more output and therefore have to be compensated by (weakly) higher consumption. Consequently, $c$ will be a non-decreasing function. We therefore impose the normalization that $c(\underline{\omega})=0$. Together with the assumption that the support of the distribution $G$ is bounded from below by 0 this implies that non-negativity constraints on consumption levels can be safely ignored in the following. An admissible policy has to satisfy the following incentive compatibility constraints: For all $w$ and $w^{\prime}$,

$$
c(\omega)-\tilde{v}(\omega, y(\omega)) \geq c\left(\omega^{\prime}\right)-\tilde{v}\left(\omega, y\left(\omega^{\prime}\right)\right) .
$$

In addition, policies have to be feasible which requires that

$$
\int_{0}^{\infty} x d G(x)+E[c(\omega)] \leq e+E[y(\omega)] .
$$

Finally, we assume that the time that individuals can devote to the generation of income is bounded. For every type $\omega$, there is an upper bound $\bar{y}(\omega)$. Hence $y: \Omega \rightarrow \mathbb{R}_{+}$can be part of an admissible policy only if, for all $\omega, y(\omega) \leq \bar{y}(\omega)$.

Taxation Principle and marginal income tax rates. According to the Taxation Principle, see Hammond (1979) and Guesnerie (1995), there is an equivalence between allocations that are admissible and allocations that are decentralizable in a system with individual-specific lump sum transfers. For the given setting, this implies that, to any admissible allocation, there exists an income tax function $T: y \mapsto T(y)$ so that

$$
y(\omega) \quad \in \quad \operatorname{argmax}_{y^{\prime} \in \mathbb{R}_{+}} \quad y^{\prime}-T\left(y^{\prime}\right)-\tilde{v}\left(\omega, y^{\prime}\right) .
$$

Consequently, to implement an admissible policy, a policy-maker can specify an income tax function, and then let individuals choose a utility-maximizing level of income. If the latter approach is taken, we can infer the marginal tax rates that are associated with any income level that lies in the image of the income schedule $y: W \rightarrow \mathbb{R}_{+}$. Assuming that the solution of the household problem above can be characterized by a first-order condition, we obtain $1-T^{\prime}(y(\omega))=\tilde{v}_{2}(w, y(\omega))$, or, equivalently,

$$
T^{\prime}(y(\omega))=1-\tilde{v}_{2}(\omega, y(\omega)) .
$$

Hence, given an income schedule $y: \Omega \rightarrow \mathbb{R}_{+}$that is part of an admissible policy, we can use equation 22 to trace out the corresponding marginal income tax rates. 
Surplus-maximization. We say that a policy is surplus-maximizing or first-best if the budget constraint in (21) holds as an equality and the provision-rule $y$ is chosen so as to maximize

$$
S(y):=E[y(\omega)]-E[\tilde{v}(\omega, y(\omega))]
$$

subject to the constraint that $y(\omega) \leq y(\bar{\omega})$, for all $\omega$. We denote the surplus-maximizing provision rule by $y^{*}$. We say that a policy $p=(y, c, G)$ is surplus-maximizing if (21) holds as an equality and $y=y^{*}$.

Welfare. We denote by

$$
U(\omega \mid p):=\int_{0}^{\infty} \Phi(x+c(\omega)-\tilde{v}(\omega, y(\omega))) d G(x)
$$

the expected utility that an individual with type $\theta$ realizes under a policy $p=(y, c, G)$. Again, the function $\Phi$ is assumed to be concave and increasing. To compute the welfare induced by a policy $p$, we use a welfare function $W(p)=E[\gamma(\omega) U(\omega \mid p)]$, where $\gamma: \Omega \rightarrow$ $\mathbb{R}_{+}$specifies the welfare weights for different types of individuals.

\subsection{The main results reconsidered}

Our main results in Theorems 1 and 2 extend to the given setting. We do not provide separate proofs. Such proofs would, with some changes in details, reiterate the arguments developed in the model of publicly provided goods. We do however provide an equilibrium characterization, see Corollaries 3 and 4 below.

By Theorem 1, equilibrium policies are surplus-maximizing. Here, this means that, for almost all $\omega \in \Omega, 1=\tilde{v}_{2}\left(\omega, y^{*}(\omega)\right)$. Hence, in a political equilibrium, there is no use of distortionary taxation, so that almost every voter faces a marginal tax rate of 0 . By Corollaries 3 and 4 below, this does not mean that there is no redistribution. The equilibrium characterization reveals that politicians engage in redistribution. However, they do so be means of pork-barrel spending, and not by making use of income taxation. By Theorem 2, there is a surplus-maximizing policy $p^{*}$ that defeats any welfare-maximizing policy. As we elaborate in more detail below, the literature on optimal income taxation has focussed on welfare-maximization as the policy-objective. By our Theorem 2, no such policy can emerge in a political equilibrium.

Again, we provide separate equilibrium characterizations for the case with a continuum of types and the case with a discrete set of types. In any case, equilibrium policies involve first-best output provision according to $y^{*}$ and transfers which are drawn from a uniform distribution on $\left[0,2\left(e+S_{v}\left(y^{*}\right)\right)\right]$, where $S_{v}\left(y^{*}\right)$ is the virtual surplus associated with output provision rule $y^{*}$. Corollaries 3 and 4 contain formal definitions of this expression. 
Corollary 3 Suppose that $\Omega=[\underline{\omega}, \bar{\omega}]$. If the set of equilibria is non-empty, then the unique symmetric equilibrium $p_{e q}=\left(y_{e q}, c_{e q}, G_{e q}\right)$ is such that:

(a) Before-tax-incomes are surplus-maximizing $y_{e q}=y^{*}$.

(b) Private goods consumption is such that for any $w \in W$,

$$
c_{e q}(\omega)=\tilde{v}\left(\omega, y^{*}(\omega)\right)-\tilde{v}\left(\underline{\omega}, y^{*}(\underline{\omega})\right)-\int_{\underline{\omega}}^{\omega} \tilde{v}_{1}\left(s, y^{*}(s)\right) d s,
$$

(c) The distribution of lump-sum transfers $G_{e q}$ is uniform on $\left[0,2\left(e+S_{v}\left(y^{*}\right)\right)\right]$, where

$$
S_{v}\left(y^{*}\right):=S\left(y^{*}\right)+\left(\tilde{v}\left(\underline{\omega}, y^{*}(\underline{\omega})\right)+E\left[\frac{1-F(\omega)}{f(\omega)} \tilde{v}_{1}\left(\omega, y^{*}(\omega)\right)\right]\right) \text {. }
$$

In the discrete type version of the model, local downward incentive constraints hold as equalities in equilibrium. This is a difference relative to the model with publicly provided goods in which local upward incentive constraints are binding. The basic logic is the same, however. In equilibrium, the pair $\left(y_{e q}, G_{e q}\right)$ is accompanied by a $c$-function so that $E[c(\omega)]$ is minimized subject to the requirement of incentive compatibility. In the model with publicly provided goods, higher types get less private goods consumption and the minimization of aggregate consumption therefore requires to make the private goods consumption of any one type as close as possible to one of the next higher type. In the income tax model, lower types get less private goods consumption and the minimization of aggregate consumption therefore requires to make the private goods consumption of any one type as close as possible to the one of the next lower type.

Corollary 4 Suppose that $\Omega=\left\{\omega_{1}, \ldots, \omega_{n}\right\}$ with $\omega_{1}=\underline{\omega}$ and $\omega_{n}=\bar{\omega}$. If the set of equilibria is non-empty, then the unique symmetric equilibrium $p_{e q}=\left(y_{e q}, c_{e q}, G_{e q}\right)$ is such that:

(a) Before-tax-incomes are surplus-maximizing $y_{e q}=y^{*}$.

(b) Private goods consumption is such that $c(\underline{\omega})=0$ and for any $\omega_{k}>\underline{\omega}$,

$$
\begin{aligned}
c_{e q}\left(\omega_{k}\right)= & \tilde{v}\left(\omega_{k}, y^{*}\left(\omega_{k}\right)\right)-\tilde{v}\left(\underline{\omega}, y^{*}(\underline{\omega})\right) \\
& -\sum_{l=1}^{k-1}\left\{\tilde{v}\left(\omega_{l+1}, y^{*}\left(\omega_{l}\right)\right)-\tilde{v}\left(\omega_{l}, y^{*}\left(\omega_{l}\right)\right)\right\} .
\end{aligned}
$$

(c) The distribution of lump-sum transfers $G_{e q}$ is uniform on $\left[0,2\left(e+S_{v}\left(y^{*}\right)\right)\right]$, where

$$
\begin{aligned}
S_{v}\left(y^{*}\right):=S & \left.y^{*}\right)+\left(\tilde{v}\left(\underline{\omega}, y^{*}(\underline{\omega})\right)\right. \\
& \left.+\sum_{l=1}^{n-1} f\left(\omega_{l}\right) \frac{1-F\left(\omega_{l}\right)}{f\left(\omega_{l}\right)}\left\{\tilde{v}\left(\omega_{l+1}, y^{*}\left(\omega_{l}\right)\right)-\tilde{v}\left(\omega_{l}, y^{*}\left(\omega_{l}\right)\right)\right\}\right) .
\end{aligned}
$$




\subsection{Political failures}

The literature on optimal income taxation considers the problem of choosing a tax policy $p=(y, c, G)$ so as to maximize a welfare function $W(p)$. Typically it assumed that $\Phi$ is strictly concave so that individuals are risk averse. Then, under a welfare-maximizing policy the lottery $G$ is degenerate and assigns mass 1 to $e+S_{v}(y)$. Thus, we can identify pork-barrel spending according to $G_{e q}$ as a first political failure. The remaining question then is how the income schedule that is chosen in a political equilibrium relates to the welfare-maximizing one. Welfare-maximization requires to choose $y$ so as to maximize

$$
E\left[\gamma(\omega) \Phi\left(e+S_{v}(y)+\int_{0}^{w} \tilde{v}_{1}(s, y(s)) d s\right)\right]
$$

subject to the constraint that $y$ is non-decreasing. The typical approach to solving this problem is to start with a relaxed problem in which the monotonicity constraint is not taken into account, and then to check under which conditions the solution to the relaxed problem is monotonic. The relaxed problem yields the following first order conditions, which characterize the welfare maximizing income schedule $y^{W}$ : for any type $\omega, y^{W}(\omega)$ solves

$$
T^{\prime}(y(\omega)):=1-v_{2}(\omega, y(\omega))=-\frac{1-F(\omega)}{f(\omega)}(1-\Gamma(\omega)) \tilde{v}_{12}(\omega, y(\omega)),
$$

where the expression

$$
\Gamma(\omega):=\frac{E\left[\gamma(s) \Phi^{\prime}(\cdot) \mid s \geq \omega\right]}{E\left[\gamma(s) \Phi^{\prime}(\cdot) \mid s \geq \underline{\omega}\right]}
$$

gives the average welfare weight of individuals with type $\omega$ and higher relative to the average individual. A standard result in the literature on optimal income taxation (see, e.g. Hellwig, 2007) is that optimal marginal tax rates are strictly positive, except possibly at the top and the bottom of the type distribution. In the given framework, one can use equation (27) to verify these results. Since $\tilde{v}_{12}(\omega, y)<0$, for all $\omega$ and $y$, and, under any admissible policy, $\Gamma(\omega)<1$, for all $\omega \geq \underline{\omega}$, it follows that $T^{\prime}(y(\omega))>0$, for all $\omega \in(\underline{\omega}, \bar{\omega}) .17$ If we relate this observation to Theorem 1 , we identify another political failure: in the political equilibrium marginal tax rates are equal to 0 throughout, whereas under a welfare-maximizing policy they should be positive, except at the top and the bottom. A welfare-maximizing policy uses distortionary taxation so as to redistribute between highly productive and less productive individuals. In a political equilibrium, this type of redistribution does not take place.

To sum up, from a welfare-perspective, political equilibria give rise to undesirable redistribution via pork-barrel spending, whereas the scope for desirable redistribution via income taxation remains unused.

\footnotetext{
17 A complication arises if one tries to explicitly compute optimal marginal tax rates on the basis of this formula. The reason is that, in general, the welfare weights are endogenous objects which depend themselves on the function $y^{W}$. However, under additional assumptions about the utility function $U$, the distribution $F$ and the cost-of-effort-function $y$, a formula for optimal marginal tax rates can be derived which depends only on exogenous parameters, see Diamond (1998).
} 


\section{Existence}

The following Proposition provides a necessary and sufficient condition for the existence of a Nash equilibrium in pure strategies. The Proposition refers to the policy $p_{e q}=$ $\left(q_{e q}, c_{e q}, G_{e q}\right)$ which has been characterized in Corollaries 1, 2, 3, and 4.

Proposition 2 An equilibrium exists if and only if there is no admissible policy $p$ with $\Pi^{1}\left(p, p_{e q}\right)>\frac{1}{2}$.

Proof By Theorem 1, if the set of equilibria is non-empty, then $\left(p_{e q}, p_{e q}\right)$ is a Nash equilibrium. This implies in particular, that there is no policy $p$ with $\Pi^{1}\left(p, p_{e q}\right)>\frac{1}{2}$. Obviously, the converse implication is also true: if there is no policy $p$ with $\Pi^{1}\left(p, p_{e q}\right)>\frac{1}{2}$, then $\left(p_{e q}, p_{e q}\right)$ is a Nash equilibrium, and hence, an equilibrium exists.

According to the Proposition, a pure strategy equilibrium exists if and only if there is no policy that wins a majority against the equilibrium candidate $p_{e q}$. This condition is useful: since we have a characterization of $p_{e q}$ in terms of the primitives of the model, equilibrium existence can be checked by investigating whether there is a best-response to $p_{e q}$ that generates a vote share that exceeds $\frac{1}{2}$.

Whether or not a pure strategy equilibrium exists is not only a technical question. Non-existence of a pure strategy equilibrium can be interpreted as a political failure. It follows from the proof of Theorem 1 that any equilibrium in which both politicians propose a surplus-maximizing policy with probability 1 has to be a symmetric equilibrium in which both politicians propose $p_{e q}$. Consequently, in any mixed strategy equilibrium, policies that are not first-best Pareto-efficient will be played with positive probability.

In the following, we use Proposition 2 to derive conditions for the existence of a pure strategy equilibrium for two special cases of our general framework. We first look at a degenerate problem of public-goods provision in which all individuals have the same type. We use this example to show that existence may indeed fail for particular parameter constellations. We then look at a "more natural" setup with two types - which implies that incentive compatibility constraints have bite - and provide a condition under which the existence of a pure strategy equilibrium is guaranteed. The second example is framed as a problem of redistributive income taxation.

\subsection{A one type economy with an indivisible public good}

We consider a special case of the model in Section 4: the set $\Theta$ is a singleton, so that all individuals have the same type, which we denote by $\theta$. There is a pure public good which comes as an indivisible unit: either the provision level is 1 , or the provision level is 0 . If the public good is provided, all individuals realize a utility of $v(\theta, 1)=\theta$. If it is not provided they realize a utility of $v(\theta, 0)=0$. The per capita cost of providing the public 
good is given by $k$. For simplicity, we assume that $\theta>k$, so that surplus-maximization requires to provide the public good, $q^{*}=1$.

Proposition 3 An equilibrium exists if and only if $\theta \geq 2 k$.

Proof The normalization $c(\bar{\theta})=0$ applied to the given setup with a single type implies that $c(\theta)=0$. An admissible policy is thus a pair $p=(q, G)$, where $q \in\{0,1\}$ and

$$
\int_{0}^{\infty} x d G(x) \leq e-k q
$$

If we adapt our equilibrium characterization to this setup, we obtain the equilibrium candidate $p_{e q}=\left(q^{e q}, G_{e q}\right)$, which is such that $q_{e q}=q^{*}=1$ and $G_{e q}$ is a uniform distribution on $[0,2(e-k)]$. An equilibrium exists if and only if there is no policy that wins a majority against $p_{e q}$. It follows from the arguments in the proof Lemma 3 that there is no such policy that also involves $q=1$. Hence, we can, without loss of generality, limit attention to policies that involve $q=0$. Suppose politician 1 chooses such a policy $p^{1}=\left(0, G^{1}\right)$, whereas politician 2 chooses $p^{2}=p_{e q}$. Politician 1 will then realize a vote share of

$$
\Pi^{1}\left(p^{1}, p_{e q}\right)=\int_{0}^{\infty} G_{e q}(x-\theta) d G^{1}(x) .
$$

Consider the problem to choose $G^{1}$ so as to maximize this expression subject to the constraint that $\int_{0}^{\infty} x d G^{1}(x) \leq e$. Since $G_{e q}$ is uniform on $[0,2(e-k)]$, the optimal $G^{1}$ does not involve offers strictly larger than $\theta+2(e-k)$ : a voter who received such an offer would vote for politician 1 with probability 1 . The same probability could be generated with an offer that is exactly equal to $\theta+2(e-k)$ and hence less costly. Hence, the support of $G^{1}$ is a subset of $[0, \theta+2(e-k)]$ and the optimization problem can be rewritten as: Choose $G^{1}$ so as to maximize

$$
\Pi^{1}\left(p^{1}, p_{e q}\right)=\int_{0}^{\theta+2(e-k)} \max \left\{0, \frac{x-\theta}{2(e-k)}\right\} d G^{1}(x)
$$

subject to $\int_{0}^{\theta+2(e-k)} x d G^{1}(x) \leq e$. Upon exploiting the convexity of the objective function, one can show that it is optimal to choose $G^{1}$ such that only an offer of 0 and an offer of $\theta+2(e-k)$ are made with positive probability ${ }^{18}$ Denote by $\bar{G}^{1}$ the probability that politi-

\footnotetext{
${ }^{18}$ Here is a sketch of the formal argument. Offers in $] 0, \theta[$ will be made with probability zero, because they yield a zero probability of winning the voter but require more resources than the offer of zero. Hence, the support of $G^{1}$ is contained in $0 \cup[\theta, \theta+2(e-k)]$. Now suppose that offers in an interval $[\underline{x}, \bar{x}] \subset] \theta, \theta+2(e-k)[$ are made with positive probability. One can show that a decrease of the probability of offers in that interval accompanied by a simultaneous increase of the probability that an offer of $\theta+2(e-k)$ is made $-\mathrm{w}$ here these changes are such that the budget constraint $\int_{0}^{\theta+2(e-k)} x d G(x)=e$ remains intact - yields an increase of $\Pi^{1}\left(p^{1}, p_{e q}\right)$. This shows that it cannot be optimal to make offers that belong to $] \theta, \theta+2(e-k)[$.
} 
cian 1 offers $\theta+2(e-k)$. It follows from the resource constraint $\int_{0}^{\theta+2(e-k)} x d G^{1}(x)=e$ that $\bar{G}^{1}=\frac{e}{\theta+2(e-k)}$. This yields a vote share of $\Pi^{1}\left(p^{1}, p_{e q}\right)=\bar{G}^{1}=\frac{e}{\theta+2(e-k)}$. Thus, an equilibrium exists if and only if this vote share is below $\frac{1}{2}$, i.e. if and only if

$$
\frac{e}{\theta+2(e-k)} \leq \frac{1}{2} \quad \Longleftrightarrow \quad \theta \geq 2 k
$$

This observation shows that, for a model with complete information, the existence of a surplus-maximizing pure strategy equilibrium cannot be taken for granted. If $\theta>k$, then surplus-maximization requires to provide the public good. If at the same time $\theta<2 k$, then it is possible to defeat the surplus-maximizing policy $p_{e q}$ by offering a transfer of $\theta+2(e-k)$ to more than half of the electorate. Any voter who receives such an offer will prefer the inefficient policy over $p_{e q}$. If the benefit from public-goods provision is sufficiently large, then the fraction of voters that can be attracted in this manner is smaller than $\frac{1}{2}$ which implies that an equilibrium exists. ${ }^{19}$

\subsection{A two type-model of income taxation}

We consider a model of income taxation with two-types, so that $\Omega=\left\{\omega_{1}, \omega_{2}\right\}$.

Proposition 4 Suppose that $\bar{y}\left(\omega_{1}\right)=\operatorname{argmax}_{y} y-\tilde{v}(\omega, y)$. Then an equilibrium exists.

A proof of the Proposition can be found in Appendix A.2. The condition $\bar{y}\left(\omega_{1}\right)=$ $\operatorname{argmax}_{y} y-\tilde{v}(\omega, y)$ is needed for the following reason: it implies that the output of a low-skilled individual is bounded from above by the surplus-maximizing output level. As we show in the Appendix, this implies that the vote-share of a politician who runs against the equilibrium candidate $p_{e q}$ is concave in pork-barrel spending. Jensen's inequality then implies that a vote-share maximizing politician refrains from offering different amounts of pork-barrel to different voters. Formally, the best he can do is to choose $G$ as a degenerate distribution. The arguments in the proof of Theorem 2 then imply that his best response is to propose the surplus-maximizing $y$-function. Absent the condition $y\left(\omega_{1}\right) \leq y^{*}\left(\omega_{1}\right)$, we can not rule out the possibility that $p_{e q}$ is defeated by a policy that involves inefficiently high output provision fo $r$ the low-skilled and an extreme distribution of pork-barrel in the electorate, i.e. a distribution so that some voters receive a lot and others do not receive anything.

\footnotetext{
${ }^{19}$ This observation has been made before by Lizzeri and Persico (2001), albeit in the context of a different setup. They assumed that $e=k$, so that the provision of the public good and redistribution via $G$ are dichotomous policy choices. They also provide a characterization of the $m$ ixed strategy equilibrium that arises if $\theta<2 k$.
} 


\section{Other models of political competition}

In this Section we briefly discuss the relation of our analysis to other models of political competition. To be specific, we focus on the model of redistributive income taxation. We first relate our analysis to various formulations of the median voter theorem. We then discuss the probabilistic voting model as an alternative framework that may be capable of generating predictions that are empirically more plausible than an analysis of "pure" competition.

\subsection{Median voter theorems}

Linear Taxes. Roberts (1977) and Meltzer and Richard (1981) study political competition using the model of linear income taxation due to Sheshinski (1972), i.e. it is assumed that there is linear tax on income and that the revenues are used in order to finance a uniform lump-sum transfer. With this policy domain, preferences are single-peaked so that the median voter's preferred policy emerges as the outcome of competition between two vote-share maximizing parties. This literature is known for the prediction, due to Meltzer and Richard (1981), that the equilibrium tax rate is an increasing function of the gap between the median voter's income and the average income in the economy. This analysis focusses on a restricted set of affine tax functions. Moreover, politicians are not given the opportunity to engage in pork-barrel spending. As follows from our analysis, a removal of these restrictions yields different results. The arguments in the proof of Theorem 2 imply that the equilibrium candidate $p_{e q}$, characterized in Corollaries 3 and 4. wins a majority against the equilibrium policy that arises in the framework of Roberts (1977) and Meltzer and Richard (1981).

Non-linear taxes in a two-class-economy. An extension of the analysis by Roberts (1977) and Meltzer and Richard (1981) to non-linear income taxes faces the difficulty that the policy space is no longer one-dimensional. This complicates the characterization of political equilibria. A tractable special case is the one with only two types of individuals, high-skilled and low-skilled. In this case, the outcome of competition between two voteshare-maximizing politicians can be characterized: they both propose the preferred policy of the bigger group 20 For instance, if the low-skilled are the bigger group, then the equilibrium tax policy is the one that maximizes a Rawlsian welfare function. Again, our Theorem 2 implies that this result does no longer hold if the policy domain includes a possibility of p ork-barrel spending. The surplus-maximizing equilibrium policy $p_{e q}$ wins a majority against the Rawlsian welfare maximum.

\footnotetext{
${ }^{20}$ Since the bigger group also contains the median level of income this observation can be viewed as an extension of the median voter theorem, see e.g. Bierbrauer and Boyer (2013) for details.
} 
Non-linear taxes and the citizen-candidate-model. Röell (2012) and Brett and Weymark (2012) study political competition over non-linear income taxes. However, they do not consider competition between vote-share-maximizing politicians. Instead, they study competition between citizen-candidates, see Osborne and Slivinski (1996) and Besley and Coate (1991). This enables them to prove a median-voter-theorem: the equilibrium tax policy is the non-linear income tax schedule that is preferred by the voter with the median level of income. We can relate our Theorem 2 also to this result: The equilibrium equilibrium policy $p_{e q}$ wins a majority against the preferred income tax schedule of the median voter.

\subsection{The probabilistic voting model}

Our model gives rise to the prediction that marginal tax rates are equal to zero at all income levels. This is of course not descriptive in an empirical sense, but an implication of our assumption that political competition is "pure": voters base their decisions only on the policies that are proposed and not on the identities of the policy-makers. Put differently, politicians have no market power. A probabilistic voting model relaxes this assumption so that each policy-maker has voters who are likely to vote for him even if he does not offer more utility than the opponent. In the following, we will first show that a probabilistic voting model can generate political equilibria with marginal tax rates that are different from zero. We will then argue that there is a close relation between our model of pure competition and the probabilistic voting model.

We restrict attention to admissible policies that involve degenerate lotteries, so that each voter receives the same lump-sum transfer equal to $e+S_{v}(y)$. In the probabilistic voting model it is assumed that, in case of having type $w$, individual $i$ votes for politician 1 provided that

$$
S_{v}\left(y^{1}\right)-h\left(w, y^{1}\right)>x_{i}^{2}+s_{v}\left(y^{2}\right)-h\left(w, y^{2}\right)
$$

where

$$
h\left(w, y^{j}\right):=\tilde{v}\left(\underline{\omega}, y^{j}(\underline{\omega})\right)+\int_{\underline{\omega}}^{w} \tilde{v}_{1}\left(s, y^{j}(s)\right) d s,
$$

tosses a coin if the two expressions are equal and votes for politician 2 otherwise. In this expression $x_{i}^{2}$ is voter $i$ 's bias towards politician 2 . It is interpreted as the maximal utility loss from accepting politician 2's policy that voter $i$ would tolerate before switching to politician 1. We assume that, the distribution of $x_{i}^{2}$, conditional on type $w$, is represented by an atomless $c d f B^{2}(\cdot \mid w)$ with density $b^{2}(\cdot \mid w)$. Politician 1's vote share can be written as a function of the two income schedules $y^{1}$ and $y^{2}$ that the two politicians propose

$$
\Pi^{1}\left(y^{1}, y^{2}\right)=E\left[B^{2}\left(S_{v}\left(y^{1}\right)-h\left(w, y^{1}\right)-S_{v}\left(y^{2}\right)+h\left(w, y^{2}\right) \mid w\right)\right]
$$


If, for simplicity, we consider a relaxed problem that disregards the monotonicity constraint on income functions, we can characterize politician 1's optimal choice of $y^{1}$ by the following first-order conditions:

$$
1-T^{\prime}\left(y^{1}(w)\right):=1-v_{2}\left(w, y^{1}(\omega)\right)=-\frac{1-F(w)}{f(w)}\left(1-\beta^{2}(w)\right) \tilde{v}_{12}\left(w, y^{1}(\omega)\right),
$$

where

$$
\beta^{2}(w)=\frac{E_{x}\left[b^{2}(\cdot \mid x) \mid x \geq w\right]}{E_{x}\left[b^{2}(\cdot \mid x)\right]}
$$

is now a measure of the political responsiveness of voters with types $w$ and higher relative to the average voter. This formula is akin to the one characterizing the welfaremaximizing tax policy in equation (27), except that the welfare weight $\Gamma(w)$ is replaced by $\beta^{2}(w)$. Suppose, without loss of generality, that politician 1 wins the election, then the first order condition in (29) also characterizes the policy that emerges in a political equilibrium. Inspection of the formula reveals that marginal tax rates are different from zero whenever $\beta^{2}(w)$ is different from 1, i.e. whenever the voters of a particular type $w$ are politically more biased than the average voter ${ }^{21}$

The relation between the probabilistic voting model and the pure model of political competition that led to Theorem 1 can be studied by comparing the objective functions that politicians maximize. As follows from the arguments in the proof of Theorem 1, in the pure model politician 1 chooses $y^{1}$ so as to maximize

$$
E\left[G^{2}\left(e+s_{v}\left(y^{1}\right)-h\left(w, y^{1}\right)+h\left(w, y^{2}\right)\right)\right],
$$

which looks similar to the objective function under probabilistic voting in 28). The main difference, apart from an additive constant, is that the distributions $B(\cdot \mid w)$ which are relevant under probabilistic voting are exogenous objects, whereas the distribution $G^{2}$ in the pure model is an endogenous object, which, in equilibrium, turns out to be a uniform distribution. Now, if all the functions $B(\cdot \mid w)$ where identical uniform distributions, then also the probabilistic voting model would give rise to marginal tax rates that are equal to 0 throughout.

The observation that $G^{2}$ is an endogenous object in the pure competition model and that the distributions $B^{2}(\cdot \mid w)$ are exogenous objects in the probabilistic voting model invites a speculative remark: consider an extended version of the probabilistic voting

\footnotetext{
${ }^{21}$ Potentially, this approach offers an explanation for observed tax and transfer systems that competes with the literature that uses a revealed preferences approach to infer a society's welfare function from the observed tax and transfers system (see, e.g., Christiansen and Jansen, 1978; Blundell, Brewer, Haan and Shephard, 2009; Bourguignon and Spadaro, 2012; Bargain, Dolls, Neumann, Peichl and Siegloch, 2011; Zoutman, Jacobs and Jongen, 2012). Others elicit preferences for distributive policies by means of surveys (see, e.g., Cowell and Schokkaert, 2001; Fong, 2001; Corneo and Grüner, 2000; Corneo and Grüner, 2002; Devooght and Schokkaert, 2003; Engelmann and Strobel, 2004; Ackert, MartinezVazquez and Rider, 2007; Weinzierl, 2012; Kuziemko, Norton, Saez and Stantcheva, 2013; Saez and Stantcheva, 2013).
} 
model in which parties can take ideological positions so as to influence the distribution of biases. If they could do this, say, subject to a constraint that the expected value of the bias cannot become unbounded, then, in equilibrium, they would choose a uniform distribution, with the implication that every party has a fifty per cent chance on every type of voter. So, we would expect the emergence of two equally strong parties with an equally distributed support in the population.

\section{Concluding remarks}

We have analyzed a model of pure competition between vote-share maximizing politicians. The "purity" had two dimensions: first there was no a-priori restriction on the set of admissible policies, politicians could propose any policy that respects the economy's information structure and the economy's resource constraint. Second, competition was pure in that politicians and voters were solely policy-oriented. There were no ideological biases, partisan motives, incumbency advantages, or other differences in valence.

A main insight is that the results are sensitive to the information structure. If all voters' preferences are observable, then groups of voters with well-defined interests can be easily identified and targeted. In such a model, surplus-maximizing policies will be defeated in the political process. By contrast, if voters have private information on their preferences, a preferential treatment of special interests becomes more difficult. If the deal for particular voter types becomes too good, then other voters will claim that they are also of the type that is eligible for the preferential treatment. This limits a politician's ability to channel resources from one group of voters to another, and, as a consequence, surplus-maximizing policies emerge in political equilibrium.

By the Taxation Principle, see Hammond (1979) and Guesnerie (1995), this finding admits a different interpretation. The incentive compatibility constraints which emerge in a private information environment are equivalent to the implementability constraints which emerge in a decentralized economic system, i.e. a system where individuals make choices subject to constraints that are affected by government policy. To give examples of such policies, think of households that choose labor supply and consumption expenditures subject to a budget constraint which is shaped by an income tax function, or think of households who decide how much publicly provided health-insurance to acquire, given a menu of tariffs. Hence, our main result is relevant for a society in which individuals are free to choose both economically and politically. According to our main result, political equilibria in such a free society, give rise to surplus-maximizing outcomes.

This result is akin to the first welfare theorem which refers to competitive equilibrium allocation, as opposed to political equilibrium allocations. There is, however, no counterpart to the second welfare theorem. Political equilibria do not give rise to welfaremaximizing outcomes, and this may be interpreted as a political failure. For a model of redistributive income taxation, in which welfare is the most plausible policy objective, our 
results imply that political equilibria give rise to an undesirable laissez-faire outcome.

\section{A Appendix}

\section{A.1 Proofs of Theorems 1 and 2 if the set of types is discrete}

Admissible policies. The following Lemma is the analogue to Lemma 1. It characterizes admissible pairs consisting of a provision rule $q$ and a lottery $G$.

Lemma A.1 Consider a pair $(q, G)$. There is a $c$-function so that $p=(q, c, G)$ is an admissible policy if and only if the following properties hold:

(i) Monotonicity: $q$ is a non-decreasing function.

(ii) Resource constraint:

$$
\int_{0}^{\infty} x d G(x) \leq e+S_{v}(q)
$$

where

$$
\begin{aligned}
S_{v}(q):= & E[v(\theta, q(\theta))]-K(q)-\left(v\left(\theta_{n}, q\left(\theta_{n}\right)\right)\right. \\
& \left.-\sum_{k=1}^{n-1} f\left(\theta_{k}\right) \frac{F\left(\theta_{k}\right)}{f\left(\theta_{k}\right)}\left\{v\left(\theta_{k+1}, q\left(\theta_{k+1}\right)\right)-v\left(\theta_{k}, q\left(\theta_{k+1}\right)\right)\right\}\right) .
\end{aligned}
$$

(iii) For each $\theta, q(\theta) \in \Lambda(q)$.

We do not provide a formal proof of this Lemma because it relies on known arguments, see e.g. Mussa and Rosen (1978) or Hellwig (2007). However, we provide a sketch of the main arguments. The monotonicity requirement in (i) is an implication of incentive compatibility and the constraint in (iii) is a physical constraint. Now suppose that we have a pair $(q, G)$ in which $q$ satisfies these requirements. The question then is whether we can find a function $c: \theta \mapsto c(\theta)$ so that the triple $p=(q, c, G)$ is admissible. To this end we study an auxiliary problem: Fix $q$ and $G$, and then choose $c$ so as to minimize $E[c(\theta)]$ subject to incentive constraints. Denote the solution to this problem by $c_{\text {min }}$. The proof is based on the following insight: If $\int_{0}^{\infty} x d G(x)+E\left[c_{\min }(\theta)\right] \leq e-K(q)$, then $p=\left(q, c_{\min }, G\right)$ is an admissible policy. If, by contrast, $\int_{0}^{\infty} x d G(x)+E\left[c_{\min }(\theta)\right]>e-K(q)$, then it is impossible to find a $c$-function so that $(q, G)$ is part of an admissible policy: If it is impossible to meet the resource constraint with the "cheapest" consumption function, then it is not possible to meet it at all.

The formula in 31 follows from $\int_{0}^{\infty} x d G(x)+E\left[c_{\min }(\theta)\right] \leq e-K(q)$, in combination with a characterization of $c_{\text {min }}$. At a solution to the auxiliary problem all local upward incentive constraints are binding, i.e., for all $\theta_{l}<\theta_{n}=\bar{\theta}$,

$$
c_{\text {min }}\left(\theta_{l}\right)+v\left(\theta_{l}, q\left(\theta_{l}\right)\right)=c_{\text {min }}\left(\theta_{l+1}\right)+v\left(\theta_{l}, q\left(\theta_{l+1}\right)\right) .
$$

This insight, in combination with the normalization that $c\left(\theta_{m}\right)=0$ makes it possible to solve for all consumption levels as a function of the provision rule $q$ : For all $\theta_{l}<\theta_{n}$,

$$
c_{\text {min }}\left(\theta_{l}\right)=v\left(\theta_{n}, q\left(\theta_{n}\right)\right)-v\left(\theta_{l}, q\left(\theta_{l}\right)\right)-\sum_{k=l}^{n-1}\left\{v\left(\theta_{k+1}, q\left(\theta_{k+1}\right)\right)-v\left(\theta_{k}, q\left(\theta_{k+1}\right)\right)\right\},
$$


and hence

$$
\begin{aligned}
E\left[c_{\min }(\theta)\right]= & -E[v(\theta, q(\theta))]+v\left(\theta_{n}, q\left(\theta_{n}\right)\right) \\
& -\sum_{k=1}^{n-1} f\left(\theta_{k}\right) \frac{F\left(\theta_{k}\right)}{f\left(\theta_{k}\right)}\left\{v\left(\theta_{k+1}, q\left(\theta_{k+1}\right)\right)-v\left(\theta_{k}, q\left(\theta_{k+1}\right)\right)\right\} .
\end{aligned}
$$

Upon substituting this expression into $\int_{0}^{\infty} x d G(x)+E\left[c_{\min }(\theta)\right] \leq e-K(q)$, we obtain the inequality in (31).

Vote-Shares. In the following, we represent an admissible policy $p^{j}=\left(q^{j}, c^{j}, G^{j}\right)$ for politician $j$ as a triple $\left(q^{j}, \Delta^{j}, G^{j}\right)$ in which $\Delta^{j}: \theta \mapsto \Delta^{j}(\theta)$ is defined such that

$$
c^{j}\left(\theta_{l}\right)=c_{\min }^{j}\left(\theta_{l}\right)+\Delta^{j}\left(\theta_{l}\right) .
$$

Lemma A.2 Let $p^{j}=\left(q^{j}, \Delta^{j}, G^{j}\right)$ be an admissible policy. Then, for all $\theta, \Delta^{j}(\theta) \geq 0$.

Proof The local upward incentive-compatibility constraints, for all $\theta_{l}<\theta_{n}$,

$$
c\left(\theta_{l}\right)+v\left(\theta_{l}, q\left(\theta_{l}\right)\right) \geq c\left(\theta_{l+1}\right)+v\left(\theta_{l}, q\left(\theta_{l+1}\right)\right)
$$

imply, in particular that, for any $\theta_{l}<\theta_{n}$,

$$
\begin{aligned}
c\left(\theta_{l}\right) \geq & c\left(\theta_{n}\right)+v\left(\theta_{n}, q\left(\theta_{n}\right)\right)-v\left(\theta_{l}, q\left(\theta_{l}\right)\right)-\sum_{k=l}^{n-1}\left\{v\left(\theta_{k+1}, q\left(\theta_{k+1}\right)\right)-v\left(\theta_{k}, q\left(\theta_{k+1}\right)\right)\right\} \\
& =v\left(\theta_{n}, q\left(\theta_{n}\right)\right)-v\left(\theta_{l}, q\left(\theta_{l}\right)\right)-\sum_{k=l}^{n-1}\left\{v\left(\theta_{k+1}, q\left(\theta_{k+1}\right)\right)-v\left(\theta_{k}, q\left(\theta_{k+1}\right)\right)\right\} \\
& =c_{\min }\left(\theta_{l}\right)
\end{aligned}
$$

where the equality in the second line follows from $c\left(\theta_{n}\right)=c_{\min }\left(\theta_{n}\right)=0$ and the equality in the third line follows from 32 .

Upon using (32), the utility that an individual of type $\theta_{l}$ derives form $\left(c^{j}, q^{j}, \Delta^{j}\right)$ can be written as

$$
\begin{aligned}
c^{j}\left(\theta_{l}\right)+v\left(\theta_{l}, q^{j}\left(\theta_{l}\right)\right)= & \Delta^{j}\left(\theta_{l}\right)+c_{\min }^{j}\left(\theta_{l}\right)+v\left(\theta_{l}, q^{j}\left(\theta_{l}\right)\right) \\
= & \Delta^{j}\left(\theta_{l}\right)+v\left(\theta_{n}, q^{j}\left(\theta_{n}\right)\right) \\
& -\sum_{k=l}^{n-1}\left\{v\left(\theta_{k+1}, q^{j}\left(\theta_{k+1}\right)\right)-v\left(\theta_{k}, q^{j}\left(\theta_{k+1}\right)\right)\right\} .
\end{aligned}
$$

Thus, taking account of pork-barrel spending, the probability that any one voter $i$ votes for politician 1 is equal to the probability of the event

$$
x_{i}^{2} \leq x_{i}^{1}+h\left(\theta, q^{1}\right)+\Delta^{1}(\theta)-\left(h\left(\theta, q^{1}\right)+\Delta^{2}(\theta)\right) .
$$

where

$$
h\left(\theta_{l}, q^{j}\right):=v\left(\theta_{n}, q\left(\theta_{n}\right)\right)-\sum_{k=l}^{n-1}\left\{v\left(\theta_{k+1}, q\left(\theta_{k+1}\right)\right)-v\left(\theta_{k}, q\left(\theta_{k+1}\right)\right)\right\},
$$


for $\theta_{l}<\theta_{n}$, and

$$
h\left(\theta_{n}, q^{j}\right):=v\left(\theta_{n}, q\left(\theta_{n}\right)\right) .
$$

If the distributions $G^{1}$ and $G^{2}$ are atomless the vote share of politician 1 can be written as

$$
\Pi^{1}\left(p^{1}, p^{2}\right):=E\left[\int_{\mathbb{R}_{+}} G^{2}\left(x_{i}^{1}+h\left(\theta, q^{1}\right)-h\left(\theta, q^{2}\right)+\Delta^{1}(\theta)-\Delta^{2}(\theta)\right) d G^{1}\left(x_{i}^{1}\right)\right] .
$$

For later reference we note that

$$
E\left[h\left(\theta, q^{j}\right)\right]=v\left(\theta_{n}, q\left(\theta_{n}\right)\right)-\sum_{k=1}^{n-1} f\left(\theta_{k}\right) \frac{F\left(\theta_{k}\right)}{f\left(\theta_{k}\right)}\left\{v\left(\theta_{k+1}, q\left(\theta_{k+1}\right)\right)-v\left(\theta_{k}, q\left(\theta_{k+1}\right)\right)\right\} .
$$

and

$$
\begin{aligned}
E\left[c^{j}(\theta)\right] & =E\left[c_{\min }^{j}(\theta)\right]+E\left[\Delta^{j}(\theta)\right] \\
& =-E\left[v\left(\theta, q^{j}(\theta)\right)\right]+E\left[h\left(\theta, q^{j}\right)\right]+E\left[\Delta^{j}(\theta)\right],
\end{aligned}
$$

so that a policy $p^{j}=\left(q^{j}, \Delta^{j}, G^{j}\right)$ is resource feasible if and only if

$$
\int_{0}^{\infty} x d G(x) \leq e+S_{v}(q)-E\left[\Delta^{j}(\theta)\right] .
$$

\section{A.1.1 Proof of Theorem 1}

The proof of Theorem 1 follows from the sequence of Lemmas below.

Lemma A.3 If the set of equilibria is non-empty, then there exists a symmetric equilibrium.

Proof See the proof of Lemma2.

Lemma A.4 Suppose that there is a symmetric equilibrium. Denote by $\left(q_{e q}, \Delta_{e q}\right)$ the corresponding provision rules. Then, the equilibrium distribution of lump-sum transfers is a uniform distribution on $\left[0,2\left(e+S_{v}\left(q_{e q}\right)-E\left[\Delta_{e q}(\theta)\right]\right)\right]$.

Proof If a symmetric equilibrium exists, then it has to be the case that any one politician $j$ choose the distribution $G^{j}$ so as to maximize his vote share conditional on $q^{1}=q^{2}=q_{e q}$ and $\Delta^{1}=\Delta^{2}=\Delta_{e q}$. Otherwise he could increase his vote share by sticking to $\left(q_{e q}, \Delta_{e q}\right)$, but offering a different distribution of pork-barrel. Conditional on $q^{1}=q^{2}=q_{e q}$, and $\Delta^{1}=\Delta^{2}=\Delta_{e q}$ the vote share of politician 1 in 41 becomes

$$
\Pi^{1}\left(p^{1}, p^{2}\right)=\int_{\mathbb{R}_{+}} G^{2}\left(x_{i}^{1}\right) d G^{1}\left(x_{i}^{1}\right)
$$

Given $G^{2}$, he chooses $G^{1}$ so as to maximize this expression subject to the constraint that $\int_{0}^{\infty} x_{i}^{1} d G^{1}\left(x_{i}^{1}\right) \leq e+S_{v}\left(q_{e q}\right)-E\left[\Delta_{e q}(\theta)\right]$. Politician 2 solves the analogous problem. Hence, conditional on $q^{1}=q^{2}=q_{e q}$, and $\Delta^{1}=\Delta^{2}=\Delta_{e q}, G^{1}$ has to be a best response to $G^{2}$ and vice versa. This problem has been analyzed in Myerson (1993), who shows that there is a unique pair of functions $G^{1}$ and $G^{2}$ which satisfy these best response requirements and the symmetry requirement $G^{1}=G^{2}$. Accordingly, $G^{1}$ and $G^{2}$ both have to be uniform distributions on $\left[0,2\left(e+S_{v}\left(q_{e q}\right)-E\left[\Delta_{e q}(\theta)\right]\right)\right]$. 
Lemma A.5 Let $\left(q_{e q}, \Delta_{e q}\right)$ be a part of a symmetric Nash equilibrium. Let $G^{u}$ be a uniform distributions on $\left[0,2\left(e+S_{v}\left(q_{e q}\right)-E\left[\Delta_{e q}(\theta)\right]\right)\right]$. Let $G^{d}$ be a degenerate distribution which puts unit mass on $e+S_{v}\left(q_{e q}\right)-E\left[\Delta_{e q}(\theta)\right]$. If $p^{1}=\left(q_{e q}, \Delta_{e q}, G^{u}\right)$ is a best response for politician 1 against $p^{2}=\left(q_{e q}, \Delta_{e q}, G^{u}\right)$. Then $\bar{p}^{1}=\left(q_{e q}, \Delta_{e q}, G^{d}\right)$ is also a best response against $p^{2}=\left(q_{e q}, \Delta_{e q}, G^{u}\right)$.

Proof If $p^{1}=\left(q_{e q}, \Delta_{e q}, G^{u}\right)$ is a best response for politician 1 against $p^{2}=\left(q_{e q}, \Delta_{e q}, G^{u}\right)$, then it yields a vote share of $\frac{1}{2}$ since the game is symmetric. Upon evaluating the expression in 40 under the assumption that $G^{2}=G^{u}$ and $G^{1}=G^{d}$, one verifies that $\bar{p}^{1}=\left(q_{e q}, \Delta_{e q}, G^{d}\right)$ does also generate a vote share of $\frac{1}{2}$.

Lemma A.6 If $q_{e q}$ is part of a symmetric Nash equilibrium, then $q_{e q}=q^{*}$.

Proof The following observation is an implication of Lemmas A.4 and A.5. If $q_{e q}$ is part of a symmetric Nash equilibrium, then it has to solve the following constrained best response problem of politician 1: choose a provision rule $q^{1}$ so as to maximize

$$
\Pi^{1}=E\left[\int_{\mathbb{R}_{+}} G^{2}\left(x_{i}^{1}+h\left(\theta, q^{1}\right)+\Delta^{1}(\theta)-\left(h\left(\theta, q^{2}\right)+\Delta^{2}(\theta)\right)\right) d G^{1}\left(x_{i}^{1}\right)\right]
$$

subject to the following constraints: $G^{1}=G^{d}, q^{2}=q_{e q}, \Delta^{1}=\Delta^{2}=\Delta_{e q}$, and $G^{2}=G^{u}$, where $G^{u}$ and $G^{d}$ are as defined in Lemma A.5. Otherwise, politician 1 could improve upon his equilibrium payoff by deviating from $q_{e q}$, which would be a contradiction to $q_{e q}$ being part of an equilibrium.

We now characterize the solution to the constrained best-response problem. The problem can equivalently be stated as follows: Choose $q^{1}$ so as to maximize

$$
\Pi^{1}=E\left[G^{u}\left(e+S_{v}\left(q^{1}\right)-E\left[\Delta^{1}(\theta)\right]+h\left(\theta, q^{1}\right)+\Delta^{1}(\theta)-\left(h\left(\theta, q_{e q}\right)+\Delta_{e q}(\theta)\right)\right)\right] .
$$

Admissible provision rules and hence $q^{1}$ and $q_{e q}$ are bounded. The resource constraint also implies that the functions $\Delta_{e q}$ and $\Delta^{1}$ have to be bounded. Hence, the assumption that $e$ is sufficiently large implies that, for all $\left(q^{1}, \Delta^{1}\right)$ and for all $\theta \in \Theta$,

$$
e+S_{v}\left(q^{1}\right)-E\left[\Delta^{1}(\theta)\right]+h\left(\theta, q^{1}\right)+\Delta^{1}(\theta)-\left(h\left(\theta, q_{e q}\right)-\Delta_{e q}(\theta)\right) \geq 0 .
$$

It also implies that, for all $q^{1}$ and for all $\theta \in \Theta$,

$$
e+S_{v}\left(q^{1}\right)-E\left[\Delta^{1}(\theta)\right]+h\left(\theta, q^{1}\right)+\Delta^{1}(\theta)-\left(h\left(\theta, q_{e q}\right)-\Delta_{e q}(\theta)\right) \leq 2\left(e+S_{v}\left(q_{e q}\right)-E\left[\Delta_{e q}(\theta)\right]\right) .
$$

Hence, for all $\theta$,

$$
\begin{gathered}
G^{u}\left(e+S_{v}\left(q^{1}\right)-E\left[\Delta^{1}(\theta)\right]+h\left(\theta, q^{1}\right)+\Delta^{1}(\theta)-\left(h\left(\theta, q_{e q}\right)-\Delta_{e q}(\theta)\right)\right) \\
=\frac{e+S_{v}\left(q^{1}\right)-E\left[\Delta^{1}(\theta)\right]+h\left(\theta, q^{1}\right)+\Delta^{1}(\theta)-\left(h\left(\theta, q_{e q}\right)-\Delta_{e q}(\theta)\right)}{2\left(e+S_{v}\left(q_{e q}\right)-E\left[\Delta_{e q}(\theta)\right]\right)},
\end{gathered}
$$

so that the objective in 42 becomes

$$
\Pi^{1}=E\left[\frac{e+S_{v}\left(q^{1}\right)-E\left[\Delta^{1}(\theta)\right]+h\left(\theta, q^{1}\right)+\Delta^{1}(\theta)-\left(h\left(\theta, q_{e q}\right)-\Delta_{e q}(\theta)\right)}{2\left(e+S_{v}\left(q_{e q}\right)-E\left[\Delta_{e q}(\theta)\right]\right)}\right] .
$$


By equations (37) and (31),

$$
E\left[S_{v}\left(q^{1}\right)-E\left[\Delta^{1}(\theta)\right]+h\left(\theta, q^{1}\right)+\Delta^{1}(\theta)\right]=E[v(\theta, q(\theta))]-K(q)=S\left(q^{1}\right) .
$$

Upon substituting this into 43 , we obtain

$$
\Pi^{1}=\frac{e+S\left(q^{1}\right)-E\left[h\left(\theta, q_{e q}\right)-\Delta_{e q}(\theta)\right]}{2\left(e+S_{v}\left(q_{e q}\right)-E\left[\Delta_{e q}(\theta)\right]\right)} .
$$

Consequently, politician 1 chooses $q^{1}$ so as to maximize the surplus $S\left(q^{1}\right)$, which yields $q=q^{*}$.

Lemma A.7 If $\Delta_{e q}$ is part of a symmetric Nash equilibrium, then $\Delta_{e q}(\theta)=0$ for all $\theta$.

Proof Suppose that $q^{1}=q^{2}=q^{*}=q_{e q}$ and that $G^{2}$ is uniform on $\left[0,2\left(e+S_{v}\left(q_{e q}\right)-E\left[\Delta^{2}(\theta)\right]\right)\right]$.

We first show that if politician 2 chooses $\Delta^{2}(\theta)=0$, for all $\theta$, then $\Delta^{1}$ with $\Delta^{1}(\theta)=0$, for all $\theta$, is a best response for politician 1 . Politician 1's vote share is

$$
\begin{aligned}
\Pi^{1} & =E\left[\int_{\mathbb{R}_{+}} G^{2}\left(x_{i}^{1}+\Delta^{1}(\theta)\right) d G^{1}\left(x_{i}^{1}\right)\right] \\
& \leq E\left[\frac{e+S_{v}\left(q_{e q}\right)-E\left[\Delta^{1}(\theta)\right]+\Delta^{1}(\theta)}{2\left(e+S_{v}\left(q_{e q}\right)\right.}\right] \\
& =\frac{e+S_{v}\left(q_{e q}\right)}{2\left(e+S_{v}\left(q_{e q}\right)\right.}=\frac{1}{2} .
\end{aligned}
$$

Moreover, $\Pi^{1}$ equals $\frac{1}{2}$, if $\Delta^{1}(\theta)=0$, for all $\theta$ and $G^{1}$ is uniform on $\left[0,2\left(e+S_{v}\left(q^{*}\right)\right)\right]$.

Now suppose that politician 2 chooses $\Delta^{2}$ so that $\Delta^{2}(\theta)>0$ for some $\theta$. We show that politician has a best response that yields a vote share strictly larger than $\frac{1}{2}$, which is incompatible with a Nash equilibrium. Consider a policy $p^{1}$ that involves $q^{1}=q_{e q}, \Delta^{1}(\theta)=0$ for all $\theta$, and a distribution $G^{1}$ so that only an offer of 0 and an offer of $2\left(e+S_{v}\left(q_{e q}\right)-E\left[\Delta^{2}(\theta)\right]\right)$ are made with positive probability. We denote by $\bar{G}^{1}$ the probability that politician 1 offers $2\left(e+S_{v}\left(q_{e q}\right)-E\left[\Delta^{2}(\theta)\right]\right)$. Since the policy $p^{1}$ has to be resource-feasible

$$
\bar{G}^{1}=\frac{e+S_{v}\left(q_{e q}\right)}{2\left(e+S_{v}\left(q_{e q}\right)-E\left[\Delta^{2}(\theta)\right]\right)} .
$$

The vote share of politician 1 is given by

$$
\begin{aligned}
\Pi^{1} & =E\left[\int_{\mathbb{R}_{+}} G^{2}\left(x_{i}^{1}-\Delta^{2}(\theta)\right) d G^{1}\left(x_{i}^{1}\right)\right] \\
& =\bar{G}^{1} \frac{2\left(e+S_{v}\left(q_{e q}\right)-E\left[\Delta^{2}(\theta)\right]\right)-E\left[\Delta^{2}(\theta)\right]}{2\left(e+S_{v}\left(q_{e q}\right)-E\left[\Delta^{2}(\theta)\right]\right)}
\end{aligned}
$$

Now $\Pi^{1}>\frac{1}{2}$ if

$$
\begin{gathered}
\bar{G}^{1} \frac{2\left(e+S_{v}\left(q_{e q}\right)-E\left[\Delta^{2}(\theta)\right]\right)-E\left[\Delta^{2}(\theta)\right]}{2\left(e+S_{v}\left(q_{e q}\right)-E\left[\Delta^{2}(\theta)\right]\right)}>\frac{1}{2} \Leftrightarrow \\
\frac{e+S_{v}\left(q_{e q}\right)}{2\left(e+S_{v}\left(q_{e q}\right)-E\left[\Delta^{2}(\theta)\right]\right)} \frac{2\left(e+S_{v}\left(q_{e q}\right)-E\left[\Delta^{2}(\theta)\right]\right)-E\left[\Delta^{2}(\theta)\right]}{2\left(e+S_{v}\left(q_{e q}\right)-E\left[\Delta^{2}(\theta)\right]\right)}>\frac{1}{2} \Leftrightarrow
\end{gathered}
$$




$$
e+S_{v}\left(q_{e q}\right)-2 E\left[\Delta^{2}(\theta)\right]>0 .
$$

This last inequality is always true when $e$ is large since $\Delta^{2}(\theta)$ is bounded.

\section{A.1.2 Proof of Theorem 2}

Let $W$ be a given welfare function. Upon using the characterization of admissible policies in Lemma 1 , the welfare that is induced by an admissible policy $p=(q, G)$ is given by

$$
W(p)=E\left[\gamma(\theta) \int_{0}^{\infty} \Phi(x+h(\theta, q)+\Delta(\theta)) d G(x)\right] .
$$

Under a welfare-maximizing policy $q, \Delta$ and $G$ are chosen so as to maximize this expression subject to the constraints that (i) $q$ is a non-decreasing function, (ii) that, for all $\theta, q(\theta) \in \Lambda(q)$, and finally, that the resource constraint holds as an equality, i.e. that $\int_{0}^{\infty} x d G(x)=e+S_{v}(q)-$ $E[\Delta(\theta)]$. Now, suppose that individuals are risk averse. Then the function $\Phi$ is strictly concave, so that, by Jensen's inequality,

$$
\begin{aligned}
& E\left[\gamma(\theta) \int_{0}^{\infty} \Phi(x+h(\theta, q)+\Delta(\theta)) d G(x)\right] \\
& <E\left[\gamma(\theta) \Phi\left(e+S_{v}(q)-E[\Delta(\theta)]+x+h(\theta, q)+\Delta(\theta)\right)\right],
\end{aligned}
$$

for any non-degenerate distribution $G$, and any given pair $(q, \Delta)$. Hence, a welfare-maximizing policy consists of a degenerate distribution $G_{q}^{d}$ which puts unit mass on $e+S_{v}(q)-E[\Delta(\theta)]$ and a pair $(q, \Delta)$ which maximizes

$$
E\left[\gamma(\theta) \Phi\left(e+S_{v}(q)-E[\Delta(\theta)]+h(\theta, q)+\Delta(\theta)\right)\right]
$$

subject to the constraints of incentive compatibility, that $q$ is a non-decreasing function and that, for all $\theta, q(\theta) \in \Lambda(q)$. We will denote such a policy henceforth by $p^{W}=\left(q^{W}, \Delta^{W}, G_{q^{W}}^{d}\right)$. Now consider a policy $p^{*}=\left(q^{*}, \Delta^{*}, G^{*}\right)$, where $q^{*}$ is the surplus-maximizing provision rule and $G^{*}$ is a uniform distribution on $\left[0,2\left(e+S_{v}\left(q^{*}\right)\right)\right]$ and $\Delta^{*}(\theta)=0$, for all $\theta$. We will now show that $\Pi_{1}\left(p^{W}, p^{*}\right) \leq \frac{1}{2}$, with a strict inequality whenever $q^{W} \neq q^{*}$. By the arguments in the proof of Lemma A.6,

$$
\begin{aligned}
\Pi_{1}\left(p^{W}, p^{*}\right) & =\frac{e+S\left(q^{W}\right)-E\left[h\left(\theta, q^{*}\right)\right]}{2\left(e+S_{v}\left(q^{*}\right)\right)} \\
& \leq \frac{e+S\left(q^{*}\right)-E\left[h\left(\theta, q^{*}\right)\right]}{2\left(e+S_{v}\left(q^{*}\right)\right)} \\
& =\frac{e+S_{v}\left(q^{*}\right)}{2\left(e+S_{v}\left(q^{*}\right)\right)} \\
& =\frac{1}{2},
\end{aligned}
$$

where the inequality in the second line is strict whenever $q^{W} \neq q^{*}$ and the equality in the third line follows from (37) and (31).

\section{A.2 Proof of Proposition 4}

The structure of the proof of Proposition 4 follows four steps: 
Step 1. For a model with two types, the equilibrium candidate $p_{e q}=\left(y_{e q}, c_{e q}, G_{e q}\right)$ looks as follows: the pre tax-incomes are surplus-maximizing, so that, for any $k \in\{1,2\}, y_{e q}\left(\omega_{k}\right)=$ $y^{*}\left(\omega_{k}\right)=\operatorname{argmax}_{y} y-\tilde{v}\left(\omega_{k}, y\right)$; the consumption function $c_{e q}$ is such that $c_{e q}\left(\omega_{1}\right)=0$, and $c_{e q}\left(\omega_{2}\right)=\tilde{v}\left(\omega_{2}, y^{*}\left(\omega_{2}\right)\right)-\tilde{v}\left(\omega_{2}, y^{*}\left(\omega_{1}\right)\right)$; and finally, $G_{e q}$ is a uniform distribution on $[0,2(e+$ $\left.\left.S_{v}\left(y^{*}\right)\right)\right]$, where

$$
S_{v}\left(y^{*}\right):=S\left(y^{*}\right)+\tilde{v}\left(\omega_{1}, y^{*}\left(\omega_{1}\right)\right)+f_{2}\left(\tilde{v}\left(\omega_{2}, y^{*}\left(\omega_{1}\right)\right)-\tilde{v}\left(\omega_{1}, y^{*}\left(\omega_{1}\right)\right)\right),
$$

and

$$
S\left(y^{*}\right):=f_{1}\left(y^{*}\left(\omega_{1}\right)-\tilde{v}\left(\omega_{1}, y^{*}\left(\omega_{1}\right)\right)\right)+f_{2}\left(y^{*}\left(\omega_{2}\right)-\tilde{v}\left(\omega_{2}, y^{*}\left(\omega_{2}\right)\right)\right) .
$$

We now check whether this policy can be defeated. Suppose that politician 1 chooses an arbitrary policy $p^{1}=\left(y^{1}, c^{1}, G^{1}\right)$ with $c^{1}\left(\omega_{1}\right)=0$ whereas politician behaves according to the equilibrium candidate $p_{e q}$. Politician 1 realizes a vote share of

$$
\begin{aligned}
\Pi^{1}\left(p, p_{e q}\right)= & f_{1} \int_{0}^{\infty} G_{e q}\left(x-\tilde{v}\left(\omega_{1}, y^{1}\left(\omega_{1}\right)\right)+\tilde{v}\left(\omega_{1}, y^{*}\left(\omega_{1}\right)\right)\right) d G^{1}(x) \\
& +f_{2} \int_{0}^{\infty} G_{e q}\left(x+c^{1}\left(\omega_{2}\right)-\tilde{v}\left(\omega_{2}, y^{1}\left(\omega_{2}\right)\right)-\left(c_{e q}\left(\omega_{2}\right)-\tilde{v}\left(\omega_{2}, y^{*}\left(\omega_{2}\right)\right)\right)\right) d G^{1}(x) \\
= & f_{1} \int_{0}^{\infty} G_{e q}\left(x-\tilde{v}\left(\omega_{1}, y^{1}\left(\omega_{1}\right)\right)+\tilde{v}\left(\omega_{1}, y^{*}\left(\omega_{1}\right)\right)\right) d G^{1}(x) \\
& +f_{2} \int_{0}^{\infty} G_{e q}\left(x+c^{1}\left(\omega_{2}\right)-\tilde{v}\left(\omega_{2}, y^{1}\left(\omega_{2}\right)\right)+\tilde{v}\left(\omega_{2}, y^{*}\left(\omega_{1}\right)\right)\right) d G^{1}(x)
\end{aligned}
$$

where the second equality exploits the fact that under $p_{e q}$ downward incentive constraints hold as equalities, so that $c_{e q}\left(\omega_{2}\right)-\tilde{v}\left(\omega_{2}, y^{*}\left(\omega_{2}\right)\right)=-\tilde{v}\left(\omega_{2}, y^{*}\left(\omega_{1}\right)\right)$.

To be admissible the policy $p^{1}$ has to respect the following constraints: Upper bounds on incomes $y^{1}\left(\omega_{1}\right) \leq \bar{y}\left(\omega_{1}\right)$ and $y^{1}\left(\omega_{2}\right) \leq \bar{y}\left(\omega_{2}\right)$; incentive compatibility

$$
\tilde{v}\left(w_{1}, y^{1}\left(\omega_{2}\right)\right)-\tilde{v}\left(w_{1}, y^{1}\left(\omega_{1}\right)\right) \geq c\left(\omega_{2}\right) \geq \tilde{v}\left(w_{2}, y^{1}\left(\omega_{2}\right)\right)-\tilde{v}\left(w_{2}, y^{1}\left(\omega_{1}\right)\right),
$$

and the resource constraint

$$
\int_{0}^{\infty} x d G^{1}(x)+f_{2} c^{1}\left(\omega_{2}\right) \leq e+f_{1} y^{1}\left(\omega_{1}\right)+f_{2} y^{1}\left(\omega_{2}\right) .
$$

Step 2. We now show that, given arbitrary $y^{1}$ and $c^{1}$ that are part of an admissible policy, the objective $\Pi_{1}\left(p^{1}, p_{e q}\right)$ is a concave function of pork-barrel payments, denoted by $x$. To this end we verify that, for all $x \geq 0$,

$$
x-\tilde{v}\left(\omega_{1}, y^{1}\left(\omega_{1}\right)\right)+\tilde{v}\left(\omega_{1}, y^{*}\left(\omega_{1}\right)\right) \geq 0,
$$

and

$$
x+c^{1}\left(\omega_{2}\right)-\tilde{v}\left(\omega_{2}, y^{1}\left(\omega_{2}\right)\right)+\tilde{v}\left(\omega_{2}, y^{*}\left(\omega_{1}\right)\right) \geq 0 .
$$

The concavity of $\Pi^{1}$ in $x$ then follows from the fact that $G_{e q}$ is concave over the positive reals. To verify that 48) and 49 hold, note that $y^{*}\left(\omega_{1}\right)=\bar{y}\left(\omega_{1}\right)=\operatorname{argmax}_{y^{\prime} \in \mathbb{R}_{+}} y^{\prime}-\tilde{v}\left(\omega, y^{\prime}\right)$ implies 
in particular that $y^{1}\left(\omega_{1}\right) \leq y^{*}\left(\omega_{1}\right)$, for every admissible policy. Hence, $x-\tilde{v}\left(\omega_{1}, y^{1}\left(\omega_{1}\right)\right)+$ $\tilde{v}\left(\omega_{1}, y^{*}\left(\omega_{1}\right)\right) \geq 0$, for all $x \geq 0$. Incentive compatibility, see (46), implies that

$$
x+c^{1}\left(\omega_{2}\right)-\tilde{v}\left(\omega_{2}, y^{1}\left(\omega_{2}\right)\right)+\tilde{v}\left(\omega_{2}, y^{*}\left(\omega_{1}\right)\right) \geq x-\tilde{v}\left(w_{2}, y^{1}\left(\omega_{1}\right)\right)+\tilde{v}\left(\omega_{2}, y^{*}\left(\omega_{1}\right)\right) \geq 0,
$$

where the second inequality follows, once more, from $y^{1}\left(\omega_{1}\right) \leq y^{*}\left(\omega_{1}\right)$.

Step 3. Consider the problem to choose $p^{1}=\left(y^{1}, c^{1}, G^{1}\right)$ so as to maximize $\Pi_{1}\left(p^{1}, p_{e q}\right)$ subject to the requirement that $p^{1}$ is admissible. Since, for given $y^{1}$ and $c^{1}, \Pi_{1}$ is concave in $x$, Jensen's inequality implies that there is a best response where $G^{1}$ is a degenerate distribution that puts unit mass on $r^{1}:=e+f_{1} y^{1}\left(\omega_{1}\right)+f_{2} y^{1}\left(\omega_{2}\right)-f_{2} c^{1}\left(\omega_{2}\right)$. This yields a vote share of

$$
\begin{aligned}
\Pi^{1}\left(p^{1}, p_{e q}\right)= & f_{1} G_{e q}\left(r^{1}-\tilde{v}\left(\omega_{1}, y^{1}\left(\omega_{1}\right)\right)+\tilde{v}\left(\omega_{1}, y^{*}\left(\omega_{1}\right)\right)\right) \\
& +f_{2} G_{e q}\left(r^{1}+c^{1}\left(\omega_{2}\right)-\tilde{v}\left(\omega_{2}, y^{1}\left(\omega_{2}\right)\right)+\tilde{v}\left(\omega_{2}, y^{*}\left(\omega_{1}\right)\right)\right) \\
= & f_{1} \min \left\{1, \frac{r^{1}-\tilde{v}\left(\omega_{1}, y^{1}\left(\omega_{1}\right)\right)+\tilde{v}\left(\omega_{1}, y^{*}\left(\omega_{1}\right)\right)}{2\left(e+S_{v}\left(y^{*}\right)\right)}\right\} \\
& +f_{2} \min \left\{1, \frac{r^{1}+c^{1}\left(\omega_{2}\right)-\tilde{v}\left(\omega_{2}, y^{1}\left(\omega_{2}\right)\right)+\tilde{v}\left(\omega_{2}, y^{*}\left(\omega_{1}\right)\right)}{2\left(e+S_{v}\left(y^{*}\right)\right)}\right\} \\
= & f_{1} \frac{r^{1}-\tilde{v}\left(\omega_{1}, y^{1}\left(\omega_{1}\right)\right)+\tilde{v}\left(\omega_{1}, y^{*}\left(\omega_{1}\right)\right)}{2\left(e+S_{v}\left(y^{*}\right)\right)} \\
& +f_{2} \frac{r^{1}+c^{1}\left(\omega_{2}\right)-\tilde{v}\left(\omega_{2}, y^{1}\left(\omega_{2}\right)\right)+\tilde{v}\left(\omega_{2}, y^{*}\left(\omega_{1}\right)\right)}{2\left(e+S_{v}\left(y^{*}\right)\right)} \\
= & \frac{e+S\left(y^{1}\right)+\tilde{v}\left(\omega_{1}, y^{*}\left(\omega_{1}\right)\right)+f_{2}\left(\tilde{v}\left(\omega_{2}, y^{*}\left(\omega_{1}\right)\right)-\tilde{v}\left(\omega_{1}, y^{*}\left(\omega_{1}\right)\right)\right)}{2\left(e+S_{v}\left(y^{*}\right)\right)}
\end{aligned}
$$

where the third equality follows from our assumptions that $e$ is a sufficiently large number and that $y\left(\omega_{1}\right)$ and $y\left(\omega_{2}\right)$ are bounded from above.

Step 4. We can now complete the proof. The argument in Step 3 implies that, for any admissible $p^{1}=\left(y^{1}, c^{1}, G^{1}\right)$, we have

$$
\begin{aligned}
\Pi^{1}\left(p^{1}, p_{e q}\right) & =\frac{e+S\left(y^{1}\right)+\tilde{v}\left(\omega_{1}, y^{*}\left(\omega_{1}\right)\right)+f_{2}\left(\tilde{v}\left(\omega_{2}, y^{*}\left(\omega_{1}\right)\right)-\tilde{v}\left(\omega_{1}, y^{*}\left(\omega_{1}\right)\right)\right)}{2\left(e+S_{v}\left(y^{*}\right)\right)} \\
& \leq \frac{e+S\left(y^{*}\right)+\tilde{v}\left(\omega_{1}, y^{*}\left(\omega_{1}\right)\right)+f_{2}\left(\tilde{v}\left(\omega_{2}, y^{*}\left(\omega_{1}\right)\right)-\tilde{v}\left(\omega_{1}, y^{*}\left(\omega_{1}\right)\right)\right)}{2\left(e+S_{v}\left(y^{*}\right)\right)} \\
& =\frac{e+S_{v}\left(y^{*}\right)}{2\left(e+S_{v}\left(y^{*}\right)\right)}=\frac{1}{2} .
\end{aligned}
$$

\section{A.3 The main result in a large, but finite economy}

There are $N$ individuals. The set of individuals is denoted by $I=\{1, \ldots, N\}$. Individual $i$ has a set of types $\Theta_{i}=[\underline{\theta}, \bar{\theta}]$, which is taken to be the same for all individuals. (For brevity, we do not spell out the analysis for a discrete set of types.) If individual $i$ has type $\theta_{i}$, consumes $c_{i}$ units of a private good and $q_{i}$ units of a publicly provided good, she realizes utility of $u_{i}=c_{i}+v\left(\theta_{i}, q_{i}\right)$. The types of different individuals are taken to be the realization of iid random variables with cumulative distribution function $F$ and density $f$. In the following we write $\theta=\left(\theta_{1}, \ldots, \theta_{N}\right)$ for a generic vector of types. Occasionally, we also write $\theta=\left(\theta_{i}, \theta_{-i}\right)$. This is an abuse of notation. In the body of the text, $\theta$ referred to a typical realization of the random variable $\theta_{i}$, as opposed to the vector of types. 
Policies. A policy consists of (i) a cross-section distribution $G$ of pork-barrel spending, (ii) for each individual $i$, a function $q_{i}: \theta \mapsto q_{i}(\theta)$ that specifies $i$ 's consumption of the publicly provided good as a function of the vector of preferences, (iii) for each individual $i$, a function $c_{i}: \theta \mapsto c_{i}(\theta)$ that specifies $i$ 's private goods consumption as a function of the vector of preferences. Again, we adopt the normalization that $c_{i}(\bar{\theta})=0$. We write $q(\theta)=\left(q_{1}(\theta), \ldots, q_{N}(\theta)\right)$ for the collection of all individual consumption levels.

Admissible policies. Admissible policies have to be incentive-compatible and resourcefeasible. We introduce some notation, so as to present the incentive compatibility constraints in a concise way. Let

$$
C_{i}\left(\hat{\theta}_{i}\right):=E_{\theta_{-i}}\left[c_{i}\left(\theta_{i}, \theta_{-i}\right)\right]
$$

be the expected numéraire consumption of individual $i$ in case of communicating type $\hat{\theta}_{i}$ under a direct mechanism. Let

$$
V_{i}\left(\theta_{i}, \hat{\theta}_{i}\right):=E_{\theta_{-i}}\left[v\left(\theta_{i}, q_{i}\left(\hat{\theta}_{i}, \theta_{-i}\right)\right)\right]
$$

be $i$ 's expected utility from the publicly provided good in case of having true type $\theta_{i}$ and communicating type $\hat{\theta}_{i}$. We denote by

$$
\mathbf{U}_{i}\left(\theta_{i}, x\right)=x+U_{i}\left(\theta_{i}\right):=x+C_{i}\left(\theta_{i}\right)+V_{i}\left(\theta_{i}, \theta_{i}\right)
$$

the utility that type $\theta_{i}$ of individual $i$ realizes in a truth-telling equilibrium, provided that he receives a transfer equal to $x$. Incentive compatibility requires that for all $i, \theta_{i}$ and $\hat{\theta}_{i}$,

$$
U_{i}\left(\theta_{i}\right) \geq C_{i}\left(\hat{\theta}_{i}\right)+V_{i}\left(\theta_{i}, \hat{\theta}_{i}\right) .
$$

We require that budget balance holds in expectation so that

$$
\int_{0}^{\infty} x d G(x)+\frac{1}{N} E_{\theta}\left[\sum_{i=1}^{N} c_{i}(\theta)\right] \leq e+\frac{1}{N} E[K(q(\theta))] .
$$

A further constraints is that $q_{i}(\theta) \in \Lambda(q(\theta))$, for all $i$, and for all $\theta_{i}$. The budget constraint holds in expectation, and not in an ex post sense. This can be justified if the number $N$ of individuals is large. In this case, one can appeal to a law of large numbers so that budget balance in expectation is approximately the same as ex post budget balance. This argument is formally spelled out in Bierbrauer (2011).

The following lemma is an adaptation of Lemma 1 to the given setup with a finite number of individuals. Again, we omit a proof.

Lemma A.8 Suppose that all $q_{i}$ are continuously differentiable functions. Then, a policy $p=$ $(q, c, G)$ is admissible if and only if it satisfies the following constraints:

(i) Monotonicity: for any $\theta_{i}$, the function $V\left(\theta_{i}, \cdot\right)$ is non-decreasing.

(ii) Utility: for all $\theta$,

$$
U_{i}\left(\theta_{i}\right)=V_{i}(\bar{\theta}, \bar{\theta})-\int_{\theta}^{\bar{\theta}} V_{i 1}(s, s) d s .
$$


(iii) Resource constraint:

$$
\int_{0}^{\infty} x d G(x) \leq e+s_{v}(q)
$$

where

$$
S_{v}(q):=s(q)-\frac{1}{N}\left(\sum_{i=1}^{N} V_{i}(\bar{\theta}, \bar{\theta})-E_{\theta}\left[\sum_{i=1}^{N} \frac{F\left(\theta_{i}\right)}{f\left(\theta_{i}\right)} v_{i 1}\left(\theta_{i}, q(\theta)\right)\right]\right) .
$$

and

$$
S(q):=\frac{1}{N} E_{\theta}\left[\sum_{i=1}^{N} v\left(\theta_{i}, q_{i}(\theta)\right)-K(q(\theta))\right]
$$

(iv) For each $\theta, q(\theta) \in \Lambda(q(\theta))$.

Political competition. We assume that two vote share-maximizing politicians propose an admissible policy. Voters evaluate these policies at the ex interim stage, i.e. after having learned their types. They vote for the policy that generates more utility. Theorems 1 and 2 remain valid in the finite economy version of our model, and we refrain from providing seperate proofs. The following Proposition adapts the equilibrium characterization to the given setup.

Proposition 5 If the set of equilibria is non-empty, then the unique symmetric equilibrium $p_{e q}=\left(q_{e q}, c_{e q}, G_{e q}\right)$ is such that:

(a) The provision rule is surplus-maximizing $q_{e q}=q^{*}$.

(b) Private goods consumption is such that for any $\theta_{i} \in \Theta$,

$$
C^{e q u}\left(\theta_{i}\right)=V_{i}^{e q u}(\bar{\theta}, \bar{\theta})-V_{i}^{e q u}\left(\theta_{i}, \theta_{i}\right)-\int_{\theta}^{\bar{\theta}} V_{i 1}^{e q u}(s, s) d s
$$

(c) The distribution of lump-sum transfers $G_{e q}$ is uniform on $\left[0,2\left(e+S_{v}\left(q^{*}\right)\right)\right]$, where

$$
S_{v}\left(q^{*}\right):=S\left(q^{*}\right)-\frac{1}{N}\left(\sum_{i=1}^{N} V_{i}(\bar{\theta}, \bar{\theta})-E_{\theta}\left[\sum_{i=1}^{N} \frac{F\left(\theta_{i}\right)}{f\left(\theta_{i}\right)} v_{i 1}\left(\theta_{i}, q^{*}(\theta)\right)\right]\right) .
$$

Proposition 5 is very similar to Corollary 1. However, in a finite economy, the interpretation of the statement $q^{*}$ maximizes the (non-virtual) surplus $S(q)$ is different. Here, this means that, for every vector of preferences $\theta \in \prod_{i=1}^{N} \Theta_{i}, q(\theta)=\left(q_{1}(\theta), \ldots, q_{N}(\theta)\right)$ is chosen so as to maximize the ex-post-surplus

$$
\sum_{i=1}^{N} v\left(\theta_{i}, q_{i}(\theta)\right)-K(q(\theta)),
$$

i.e. we have a separate optimality condition for each state of the economy, or, for each constellation of preferences. In the continuum economy in the body of the text this was not the case. There, the cross-section distribution of preferences was taken to be given by $F$ and hence not to involve genuine randomness. Put differently, there was only one state of the economy for which an outcome had to be specified. 


\section{References}

Acemoglu, D., M. Golosov and A. Tsyvinski. 2008. "Political Economy of Mechanisms." Econometrica 76:619-641.

Acemoglu, D., M. Golosov and A. Tsyvinski. 2010. "Dynamic Mirrlees Taxation under Political Economy Constraints." Review of Economic Studies 77:841-881.

Ackert, L., J. Martinez-Vazquez and M. Rider. 2007. "Social Preferences and Tax Policy Design: Some Experimental Evidence." Economic Inquiry 45(3):487-501.

Al-Najjar, N. 2004. "Aggregation and the Law of Large Numbers in Large Economies." Games and Economic Behavior 47:1-35.

Bargain, O., M. Dolls, D. Neumann, A. Peichl and S. Siegloch. 2011. "Tax-Benefit Systems in Europe and the US: Between Equity and Efficiency." IZA Discussion Papers 5440 .

Baron, D.P. and J.A. Ferejohn. 1989. "Bargaining in Legislatures." American Political Science Review 83:1181-1206.

Barro, R. 1973. "The Control of Politicians: An economic model." Public Choice 14:1942.

Battaglini, M. and S. Coate. 2008. "A Dynamic Theory of Public Spending, Taxation and Debt." American Economic Review 98:201-236.

Besley, T. and S. Coate. 1991. "Public Provision of Private Goods and the Redistribution of Income." American Economic Review 81:979-984.

Besley, T. and S. Coate. 1997. "A Model of Representative Democracy.” Quarterly Journal of Economics 112:85-114.

Bierbrauer, F.J. 2011. "On the Optimality of Optimal Income Taxation." Journal of Economic Theory 146:2105-2116.

Bierbrauer, F.J. and P.C. Boyer. 2013. "Political competition and Mirrleesian income taxation: A first pass." Journal of Public Economics 103:1-14.

Blomquist, S. and V. Christiansen. 1999. "The political economy of publicly provided private goods." Journal of Public Economics 73:31-54.

Blundell, R., M. Brewer, P. Haan and A. Shephard. 2009. "Optimal income taxation of lone mothers: an empirical comparison of the UK and Germany." Economic Journal 119:F101-F121. 
Bourguignon, F. and A. Spadaro. 2012. "Tax-benefit Revealed Social Preferences." Journal of Economic Inequality 10(1):75-108.

Brett, C. and J.A. Weymark. 2012. "Citizen Candidates and Voting Over IncentiveCompatible Nonlinear Income Tax Schedules." Working Paper .

Carbonell-Nicolau, O. and E. A. Ok. 2007. "Voting over income taxation." Journal of Economic Theory 134:249-286.

Casamatta, G., H. Cremer and P. De Donder. 2010. "Repeated electoral competition over nonlinear income tax schedules." Social Choice and Welfare 35:535-574.

Christiansen, V. and E. Jansen. 1978. "Implicit Social Preferences in the Norwegian System of Indirect Taxation." Journal of Public Economics 10(2):217-245.

Corneo, G. and H.P. Grüner. 2000. "Social Limits to Redistribution." American Economic Review 90:1491-1507.

Corneo, G. and H.P. Grüner. 2002. "Individual Preferences for Political Redistribution." Journal of Public Economics 83:83-107.

Cowell, F. and E. Schokkaert. 2001. "Risk perceptions and distributional judgments." European Economic Review 45(4-6):941-952.

Crutzen, B. and N. Sahuguet. 2009. "Redistributive politics with distortionary taxation." Journal of Economic Theory 144:264-279.

d'Aspremont, C. and L. Gérard-Varet. 1979. "Incentives and Incomplete Information." Journal of Public Economics 11:25-45.

De Donder, P. and J. Hindriks. 2003. "The Politics of Progressive Income Taxation with Incentive Effects." Journal of Public Economics 87:2491-2505.

Devooght, K. and E. Schokkaert. 2003. "Responsibility-sensitive Fair Compensation in Different Cultures." Social Choice and Welfare 21:207-242.

Diamond, P.A. 1998. "Optimal Income Taxation: An Example with a U-Shaped Pattern of Optimal Marginal Tax Rates." American Economic Review 88:83-95.

Downs, A. 1957. An Economic Theory of Democracy. New York, Harper and Row.

Engelmann, D. and M. Strobel. 2004. "Inequality Aversion, Efficiency and Maximin Preferences in Simple Distribution Experiments." American Economic Review 94(4):857869.

Fahri, E. and I. Werning. 2008. "The Political Economy of Non-Linear Capital Taxation." Mimeo, MIT. 
Feldman, M. and C. Gilles. 1985. "An Expository Note on Individual Risk Without Aggregate Uncertainty." Journal of Economic Theory 35:26-32.

Ferejohn, J. 1986. "Incumbent Performance and electoral control." Public Choice 50:5-25.

Fong, C. 2001. "Social Preferences, Self-interest, and the Demand for Redistribution." Journal of Public Economics 82(2):225-246.

Grüner, H.P. and Y. Koriyama. 2012. "Public goods, participation constraints, and democracy: A possibility theorem." Game and Economic Behavior 75(1):152-167.

Green, J. and J.J. Laffont. 1977. "Characterization of Satisfactory Mechanisms for the Revelation of Preferences for Public Goods." Econometrica 45:472-487.

Guesnerie, R. 1995. A Contribution to the Pure Theory of Taxation. Cambridge University Press.

Güth, W. and M. Hellwig. 1986. "The Private Supply of a Public Good." Journal of Economics Supplement 5:121-159.

Hammond, P. 1979. "Straightforward Individual Incentive Compatibility in Large Economies." Review of Economic Studies 46:263-282.

Hellwig, M. 2007. "A Contribution to the Theory of Optimal Utilitarian Income Taxation." Journal of Public Economics 91:1449-1477.

Judd, K. 1985. "The Law of Large Numbers with a Continuum of I.I.D. Random Variables." Journal of Economic Theory 35:19-25.

Kuziemko, I., M. Norton, E. Saez and S. Stantcheva. 2013. "How Elastic are Preferences for Redistribution? Evidence from Randomized Survey Experiments." NBER Working Paper No. 18865.

Laslier, J.-F. and N. Picard. 2002. "Distributive Politics and electoral competition." Journal of Economic Theory 103:106-130.

Ledyard, J. 2006. "Voting and Efficient Public Good Mechanisms." Oxford Handbook of Political Economy. in B. Weingast and D. Wittman (eds) .

Lindbeck, A. and J. Weibull. 1987. "Balanced-budget Redistribution as the Outcome of Political Competition." Public Choice 52:273297.

Lizzeri, A. 1999. "Budget Deficits and Redistributive Politics." Review of Economic Studies 66:909-928.

Lizzeri, A. and N. Persico. 2001. "The Provision of Public Goods under Alternative Electoral Incentives." American Economic Review 91(1):225-239. 
Lizzeri, A. and N. Persico. 2004. "Why Did the Elites Extend the Suffrage? Democracy and the Scope of Government, with an Application to Britain's Age of Reform." Quarterly Journal of Economics 119(2):707-765.

Lizzeri, A. and N. Persico. 2005. "A Drawback of Electoral Competition." Journal of the European Economic Association 3(6):1318-1348.

Mailath, G. and A. Postlewaite. 1990. "Asymmetric Bargaining Procedures with Many Agents." Review of Economic Studies 57:351-367.

Martimort, D. 2001. "Optimal Taxation and Strategic Budget Deficit under Political Regime Switching." Review of Economic Studies 68:573-592.

Mas-Colell, A., M. Whinston and J. Green. 1995. Microeconomic Theory. Oxford University Press.

Meltzer, A. and S. Richard. 1981. "A Rational Theory of the Size of Government." Journal of Political Economy 89:914-927.

Milgrom, P. and I. Segal. 2002. "Envelope Theorems for Arbitrary Choice Sets." Econometrica 70:583-601.

Mirrlees, J. 1971. "An Exploration in the Theory of Optimum Income Taxation." Review of Economic Studies 38:175-208.

Mussa, M. and S. Rosen. 1978. "Monopoly and Product Quality." Journal of Economic Theory 18:301-317.

Myerson, R. 1993. "Incentives to Cultivate Favored Minorities Under Alternative Electoral Systems." American Political Science Review 87(4):856-869.

Osborne, M. and A. Rubinstein. 1994. A course in Game Theory. MIT Press, Cambridge, MA.

Osborne, M. and A. Slivinski. 1996. "A Model of Political Competition With CitizenCandidates." Quarterly Journal of Economics 111:65-96.

Röell, A.A. 2012. "Voting over Nonlinear Income Tax Schedules." Working Paper.

Roberson, B. 2006. "The Colonel Blotto game." Economic Theory 29:1-24.

Roberson, B. 2008. "Pork-Barrel Politics, Tagetable Policies, and Fiscal Federalism." Journal of the European Economic Association 6(4):819-844.

Roberts, K. 1977. "Voting over Income Tax Schedules." Journal of Public Economics 8:329-340. 
Roemer, J.E. 1999. "The Democratic Political Economy of Progressive Income Taxation." Econometrica 134:1-19.

Roemer, J.E. 2011. "A theory of income taxation where politicians focus upon core and swing voters." Social Choice and Welfare 36:383-421.

Saez, E. 2001. "Using Elasticities to Derive Optimal Income Tax Rates." Review of Economic Studies 68:205-229.

Saez, E. and S. Stantcheva. 2013. "Generalized Social Marginal Welfare Weights for Optimal Tax Theory." NBER Working Paper No. 18835.

Sahuguet, N. and N. Persico. 2006. "Campaign spending regulation in a model of redistributive politics." Economic Theory 28:95-124.

Samuelson, P. 1954. "The Pure Theory of Public Expenditure." Review of Economics and Statistics 36:387-389.

Schmitz, P.W. and T. Tröger. 2012. "The (sub-)optimality of the majority rule." Game and Economic Behavior 74(2):651-665.

Sheshinski, E. 1972. "The Optimal Linear Income-tax." Review of Economic Studies 39:297-302.

Sun, Y. 2006. "The exact law of large numbers via Fubini extension and characterization of insurable risks." Journal of Economic Theory 126:31-69.

Weinzierl, M.C. 2012. "The Promise of Positive Optimal Taxation." NBER Working Paper No. 18599.

Zoutman, F., B. Jacobs and E. Jongen. 2012. "Revealed Social Preferences of Dutch Political Parties." Tinbergen Institution Discussion Paper. 